\title{
Magnetic Field in Reentry Flows in 2D: Eleven Species
}

\author{
Edisson Sávio de Góes Maciel $^{1^{*}}$ \\ ${ }^{1}$ Technological Institute of Aeronautics (ITA), Cx. Postal: 2029-12.243-970, São José dos Campos, SP,
} Brazil.

Author's contribution

The ESDGM author designed, analyzed, interpreted and prepared the manuscript.

Article Information

DOI: $10.9734 / J A M C S / 2017 / 36904$

Editor(s):

(1) Mohamed Rabea Eid Said, Department of Science and Mathematics, Assiut University, Egypt. Reviewers:

(1) Muammer Ozgoren, Selcuk University, Turkey (2) José Martínez Reyes, University of the Ciénega of Michoacán State, México. Complete Peer review History: http://www.sciencedomain.org/review-history/21384

Original Research Article

Received: $22^{\text {nd }}$ September 2017

Accepted: $7^{\text {th }}$ October 2017

Published: $13^{\text {th }}$ October 2017

\begin{abstract}
In this work, a study involving magnetic field actuation over reentry flows in thermochemical nonequilibrium is performed. The Euler and Navier-Stokes equations, on a finite volume and structured contexts, are studied. The Maciel algorithm used to perform the numerical experiments is centered and $2^{\text {nd }}$-order accurate. The "hot gas" hypersonic flow around a blunt body is simulated. Two time integration methods are tested: Euler Backward, and Middle Point. The reactive simulations involve Earth atmosphere of eleven species. The Dunn and Kang model with thirty-two reactions and the Park model with forty-three reactions are taken into account. The work of Gaitonde is the reference to couple the fluid dynamics and Maxwell equations of electromagnetism. The results have indicated that the Maciel scheme, employing the Dunn and Kang chemical model, using the Mavriplis dissipation model and the Euler Backward to march in time, for the inviscid case, yields the best prediction of the stagnation pressure. Moreover, the drag coefficient and the temperature peak have presented the expected behavior in the simulations.
\end{abstract}

Keywords: Hypersonic flow; Euler and Navier-Stokes equations; Maxwell equations; 11 species chemical model; Maciel scheme; reentry flows; two-dimensions.

*Corresponding author: E-mail: edissonsavio@yahoo.com.br; 


\section{NOMENCLATURES}

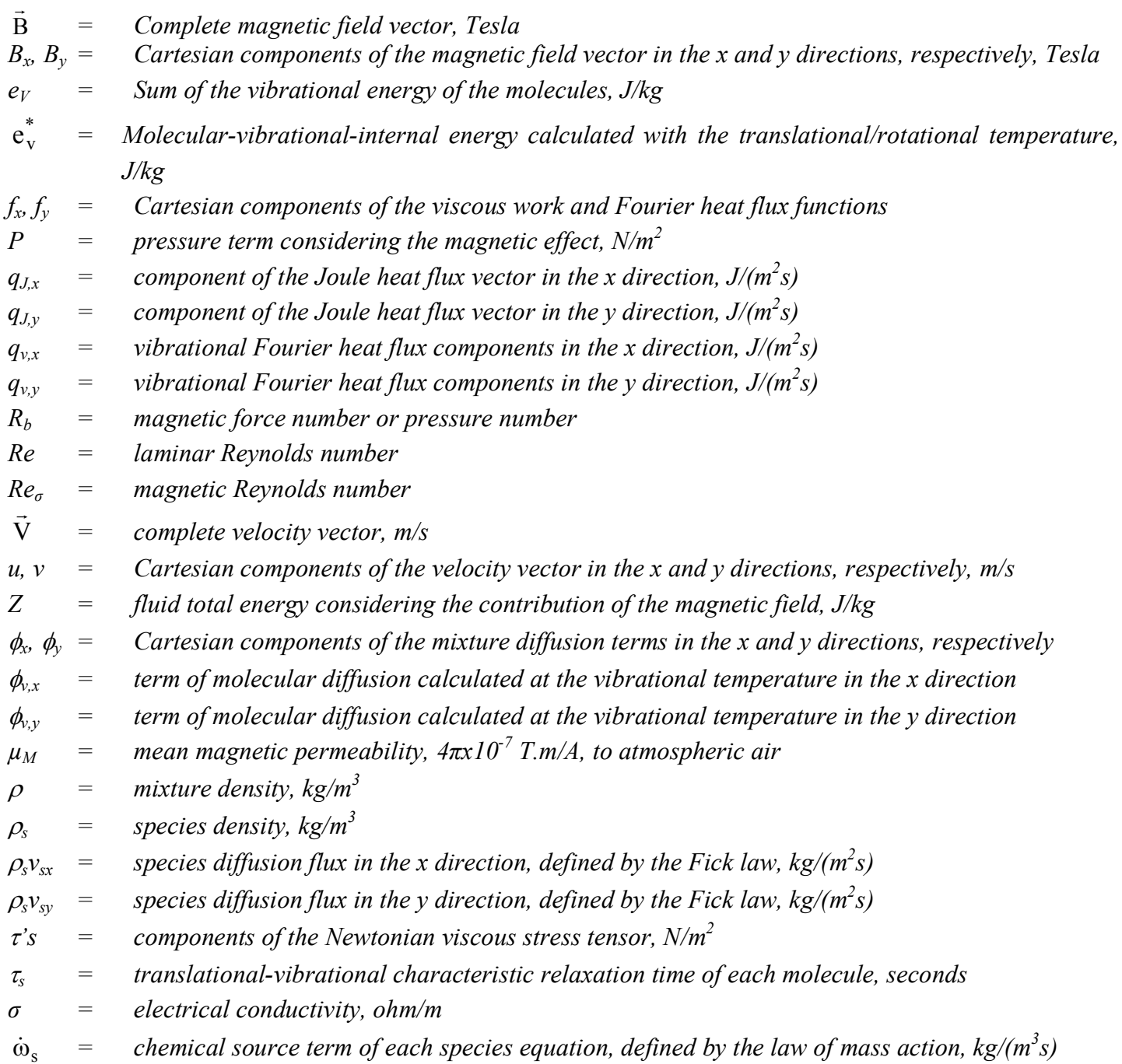

\section{Introduction}

Renewed interest in the area of hypersonic flight has brought computational fluid dynamics (CFD) to the forefront of fluid flow research [1]. Many years have seen a quantum leap in advancements made in the areas of computer systems and software which utilize them for problem solving. Sophisticated and accurate numerical algorithms are devised routinely that are capable of handling complex computational problems. Experimental test facilities capable of addressing complicated high-speed flow problems are still scarce because they are too expensive to build and sophisticated measurements techniques appropriate for such problems, such as the non-intrusive laser, are still in the development stage. As a result, CFD has become a vital tool, in some cases the only tool, in the flow research today.

The study of hypersonic flows has gained momentum with the advent of concepts like the National AeroSpace Plane (NASP) and similar transatmospheric vehicles. Under the very high velocity and temperature conditions experienced by hypersonic vehicles, departure from chemical and thermal 
equilibrium occurs. Properties of air change dramatically as new chemical species are produced at the expense of others. The simple one temperature model used to describe the energy of air becomes inapplicable, and it becomes necessary to consider one or more additional temperatures (corresponding to vibrational and electronic energies). Determination of aerothermal loads on blunt bodies in such an environment is of great importance.

In high speed flows, any adjustment of chemical composition or thermodynamic equilibrium to a change in local environment requires certain time. This is because the redistribution of chemical species and internal energies require certain number of molecular collisions, and hence a certain characteristic time. Chemical non-equilibrium occurs when the characteristic time for the chemical reactions to reach local equilibrium is of the same order as the characteristic time of the fluid flow. Similarly, thermal non-equilibrium occurs when the characteristic time for translation and various internal energy modes to reach local equilibrium is of the same order as the characteristic time of the fluid flow. Since chemical and thermal changes are the results of collisions between the constituent particles, non-equilibrium effects prevail in high-speed flows in low-density air.

In chemical non-equilibrium flows the mass conservation equation is applied to each of the constituent species in the gas mixture. Therefore, the overall mass conservation equation is replaced by as many species conservation equations as the number of chemical species considered. The assumption of thermal nonequilibrium introduces additional energy conservation equations - one for every additional energy mode. Thus, the number of governing equations for non-equilibrium flow is much bigger compared to those for perfect gas flow. A complete set of governing equations for non-equilibrium flow may be found in [2-3].

The problems of chemical non-equilibrium in the shock layers over vehicles flying at high speeds and high altitudes in the Earth's atmosphere have been discussed by several investigators ([4-7]). Most of the existing computer codes for calculating the non-equilibrium reacting flow use the one-temperature model, which assumes that all of the internal energy modes of the gaseous species are in equilibrium with the translational mode ([6-7]). It has been pointed out that such a one-temperature description of the flow leads to a substantial overestimation of the rate of equilibrium because of the elevated vibrational temperature [5]. A three-temperature chemical-kinetic model has been proposed by [8] to describe the relaxation phenomena correctly in such a flight regime. However, the model is quite complex and requires many chemical rate parameters which are not yet known. As a compromise between the three-temperature and the conventional one-temperature model, a two-temperature chemical-kinetic model has been developed ([9-10]), which is designated herein as the TTv model. The TTv model uses one temperature $\mathrm{T}$ to characterize both the translational energy of the atoms and molecules and the rotational energy of the molecules, and another temperature $\mathrm{Tv}$ to characterize the vibrational energy of the molecules, translational energy of the electrons, and electronic excitation energy of atoms and molecules. The model has been applied to compute the thermodynamic properties behind a normal shock wave in a flow through a constant-area duct ([9-10]). Radiation emission from the non-equilibrium flow has been calculated using the Non-equilibrium Air Radiation (NEQAIR) program ([11-12]). The flow and the radiation computations have been packaged into a single computer program, the Shock-Tube Radiation Program (STRAP) ([10]).

The effects associated with the interaction of magnetic forces with conducting fluid flows have been profitably employed in several applications related to nuclear and other ([13]) technologies and are known to be essential in the explanation of astrophysical phenomena. In recent years, however, the study of these interactions has received fresh impetus in the effort to solve the problems of high drag and thermal loads encountered in hypersonic flight. The knowledge that electrical and magnetic forces can have profound influence on hypersonic flow fields is not new ([14-15]) - note increased shock-standoff and reduced heat transfer rates in hypersonic flows past blunt bodies under the application of appropriate magnetic fields. The recent interest stems, however, from new revelations of a Russian concept vehicle, known as AJAX ([16]), which made extensive reference to technologies requiring tight coupling between electromagnetic and fluid dynamic phenomena. A magnetogasdynamics (MGD) generator was proposed ([17]) to extract energy from the incoming air while simultaneously providing more benign flow to combustion components downstream. The extracted energy could then be employed to increase thrust by MGD pumping of the flow exiting the 
nozzle or to assist in the generation of a plasma for injection of the body. This latter technique is known to not only reduced drag on the body but also to provide thermal protection ([18]).

In addition to daunting engineering challenges, some of the phenomena supporting the feasibility of an AJAX type vehicle are fraught with controversy (see, for example, [19]). Resolution of these issues will require extensive experimentation as well as simulation. The latter approach requires integration of several disciplines, including fluid dynamics, electromagnetics, chemical kinetics, and molecular physics amongst others. This paper describes a recent effort to integrate the first three of these, within the assumptions of ideal and non-ideal magnetogasdynamics.

In this work, a study involving magnetic field actuation over reentry flows in thermochemical nonequilibrium condition is performed. The Euler and Navier-Stokes equations, on conservative and finite volume contexts, employing structured spatial discretization, are studied. The numerical algorithm of Maciel is used to perform the reentry flow numerical experiments, which give us an original contribution to the CFD community. Two types of numerical dissipation models are applied, namely: [20-21]. The "hot gas" hypersonic flow around a blunt body, in two-dimensions, is simulated. The convergence process is accelerated to steady state condition through a spatially variable time step procedure, which has proved effective gains in terms of computational acceleration ([22-23]). Two time integration methods are tested to march the scheme in time, and it is another original contribution of this work. They are: Euler Backward, and Middle Point. The reactive simulations involve Earth atmosphere chemical model of eleven species. The [24] model with thirty-two reactions and the [25] model with forty-three reactions are taken into account. The work of [26-27] are the references ones to couple the fluid dynamics and Maxwell equations of electromagnetism based on a conservative and finite volume formalisms. The results have indicated that the Maciel scheme employing the [24] chemical model, using the [20] artificial dissipation operator and the Euler Backward method to march in time, for the inviscid case, yields the best prediction of the stagnation pressure value. Moreover, the shock-standoff distance did not suffer alteration with the increase of the magnetic field intensity, but the drag coefficient reduces in value, as well the temperature peak.

\section{Navier-stokes and Maxwell Equations}

The flow is modelled by the Navier-Stokes equations in the condition of thermochemical non-equilibrium, where the rotational and vibrational contributions are considered, and by the Maxwell equations. Once the reactive Euler equations are obtained from the reactive Navier-Stokes equations in the limit of infinity Reynolds number, only the latter are presented. The reactive formulation involves an eleven species chemical model. Details of the eleven species model implementation, as well the thermodynamic and transport properties, are described in [28-29], and the interested reader is encouraged to read these works to become aware of the present study.

The reactive Navier-Stokes equations, in thermal and chemical non-equilibrium, coupled with the Maxwell equations, were implemented on conservative and finite volume contexts, in the two-dimensional space. In this case, these equations in integral and conservative forms can be expressed by:

$$
\frac{\partial}{\partial \mathrm{t}} \int_{\mathrm{V}} \mathrm{QdV}+\int_{\mathrm{S}} \overrightarrow{\mathrm{F}} \bullet \overrightarrow{\mathrm{n}} \mathrm{d} S=\int_{\mathrm{V}} \mathrm{S}_{\mathrm{CV}} \mathrm{dV} \text {, with: } \overrightarrow{\mathrm{F}}=\left(\mathrm{E}_{\mathrm{e}}-\mathrm{E}_{\mathrm{v}}\right) \overrightarrow{\mathrm{i}}+\left(\mathrm{F}_{\mathrm{e}}-\mathrm{F}_{\mathrm{V}}\right) \overrightarrow{\mathrm{j}}
$$

where: $\mathrm{Q}$ is the vector of conserved variables, $\mathrm{V}$ is the volume of a computational cell, $\overrightarrow{\mathrm{F}}$ is the complete flux vector, $\overrightarrow{\mathrm{n}}$ is the unity vector normal to the flux face, $\mathrm{S}$ is the flux area, $\mathrm{S}_{\mathrm{CV}}$ is the chemical and vibrational source term, $E_{e}$ and $F_{e}$ are the convective flux vectors or the Euler flux vectors in the $\mathrm{x}$ and $\mathrm{y}$ directions, respectively, $E_{v}$ and $F_{v}$ are the viscous flux vectors in the $x$ and y directions, respectively. The $\vec{i}$ and $\vec{j}$ unity vectors define the Cartesian coordinate system. Seventeen (17) conservation equations are solved: one of general mass conservation, two of linear momentum conservation, one of total energy, ten of species mass conservation, one of the vibrational internal energy of the molecules, and two of the Maxwell 
equations. Therefore, one of the species is absent of the iterative process. The CFD literature recommends that the species of biggest mass fraction of the gaseous mixture should be omitted, aiming to result in a minor numerical accumulation error. To the present study, in which is chosen a chemical model of the air composed of eleven (11) chemical species, this species can be the $\mathrm{N}_{2}$ or the $\mathrm{O}_{2}$. It was chosen the $\mathrm{N}_{2}$. The vectors $\mathrm{Q}, \mathrm{E}_{\mathrm{e}}, \mathrm{F}_{\mathrm{e}}, \mathrm{E}_{\mathrm{v}}, \mathrm{F}_{\mathrm{v}}$, and $\mathrm{S}_{\mathrm{CV}}$ can, hence, be defined as follows:

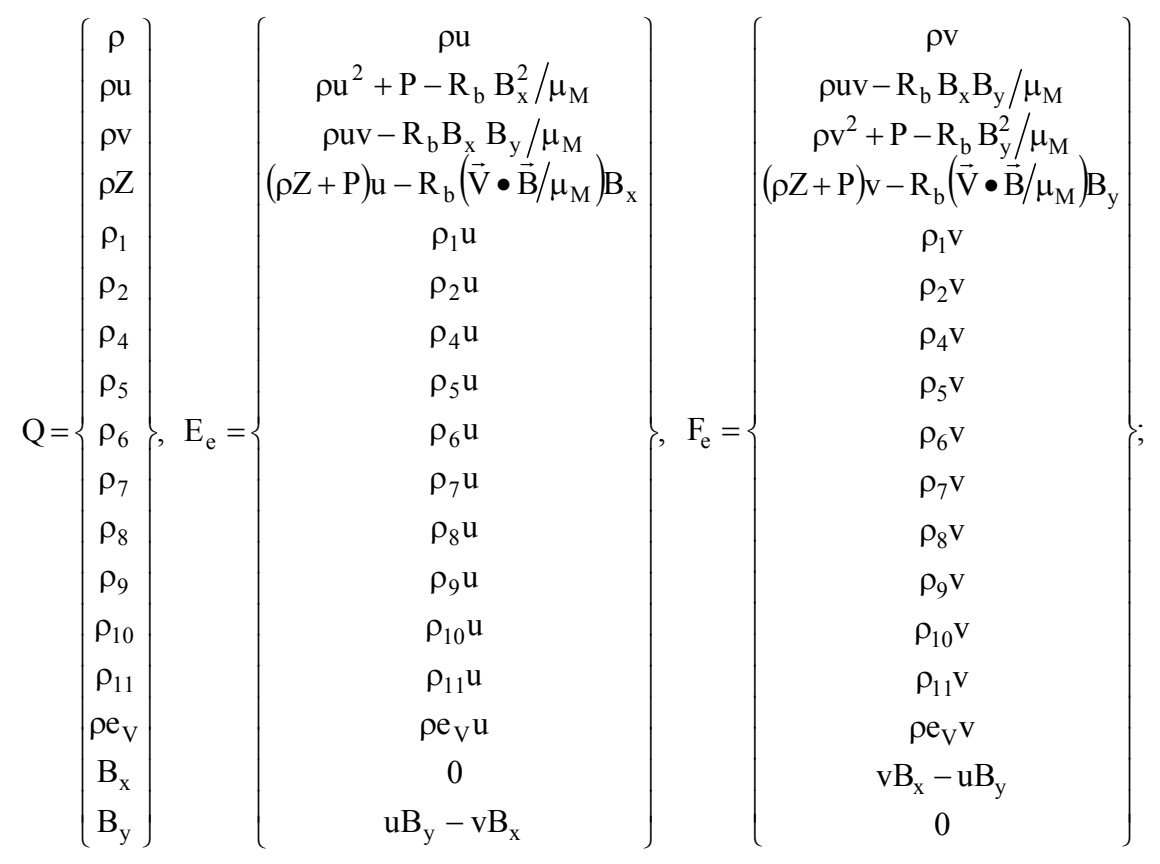

$$
\mathrm{E}_{\mathrm{v}}=\left\{\begin{array}{c}
0 \\
\tau_{\mathrm{xx}} / \operatorname{Re} \\
\tau_{\mathrm{xy}} / \operatorname{Re} \\
\left(\mathrm{f}_{\mathrm{x}}-\phi_{\mathrm{x}}\right) / \operatorname{Re}-\mathrm{q}_{\mathrm{J}, \mathrm{x}} / \operatorname{Re}_{\sigma} \\
-\rho_{1} \mathrm{v}_{1 \mathrm{x}} / \operatorname{Re} \\
-\rho_{2} \mathrm{v}_{2 \mathrm{x}} / \operatorname{Re} \\
-\rho_{4} \mathrm{v}_{4 \mathrm{x}} / \operatorname{Re} \\
-\rho_{5} \mathrm{v}_{5 \mathrm{x}} / \operatorname{Re} \\
-\rho_{6} \mathrm{v}_{6 \mathrm{x}} / \operatorname{Re} \\
-\rho_{7} \mathrm{v}_{7 \mathrm{x}} / \operatorname{Re} \\
-\rho_{8} \mathrm{v}_{8 \mathrm{x}} / \operatorname{Re} \\
-\rho_{9} \mathrm{v}_{9 \mathrm{x}} / \operatorname{Re} \\
-\rho_{10} \mathrm{v}_{10 \mathrm{x}} / \operatorname{Re} \\
-\rho_{11} \mathrm{v}_{1 \mathrm{x}} / \operatorname{Re} \\
\left(-\mathrm{q}_{\mathrm{v}, \mathrm{x}}-\phi_{\mathrm{v}, \mathrm{x}}\right) / \operatorname{Re} \\
0 \\
\left.\frac{\partial}{\operatorname{Re}} \frac{\partial}{\sigma} \frac{\mathrm{B}_{\mathrm{y}}}{\partial \mathrm{x}}\right)-\frac{\partial}{\mu_{\mathrm{M}}}\left(\frac{\mathrm{B}_{\mathrm{x}}}{\mu_{\mathrm{M}}}\right)
\end{array}\right\},
$$

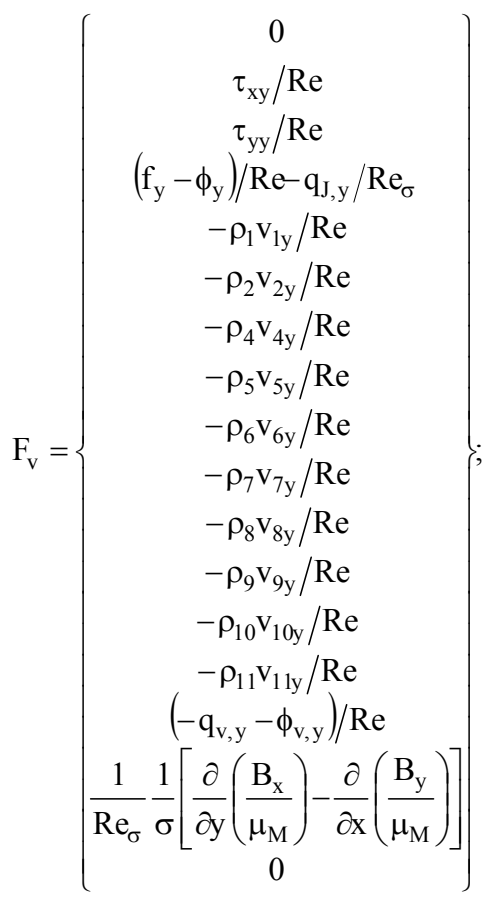




$$
\mathrm{S}_{\mathrm{CV}}=\left\{\begin{array}{c}
0 \\
0 \\
0 \\
0 \\
\dot{\omega}_{1} \\
\dot{\omega}_{2} \\
\dot{\omega}_{4} \\
\dot{\omega}_{5} \\
\dot{\omega}_{6} \\
\dot{\omega}_{7} \\
\dot{\omega}_{8} \\
\dot{\omega}_{9} \\
\dot{\omega}_{10} \\
\dot{\omega}_{11} \\
\sum_{\mathrm{s}=\mathrm{mol}} \rho_{\mathrm{s}}\left(\mathrm{e}_{\mathrm{v}, \mathrm{s}}^{*}-\mathrm{e}_{\mathrm{v}, \mathrm{s}}\right) / \tau_{\mathrm{s}}+\sum_{\mathrm{s}=\mathrm{mol}} \dot{\omega}_{\mathrm{s}} \mathrm{e}_{\mathrm{v}, \mathrm{s}} \\
0 \\
0
\end{array}\right\} .
$$

The viscous stresses, in $\mathrm{N} / \mathrm{m}^{2}$, are determined, according to a Newtonian fluid model, by:

$$
\begin{aligned}
\tau_{\mathrm{xx}} & =[2 \mu \partial \mathrm{u} / \partial \mathrm{x}-2 / 3 \mu(\partial \mathrm{u} / \partial \mathrm{x}+\partial \mathrm{v} / \partial \mathrm{y})], \tau_{\mathrm{xy}}=\mu(\partial \mathrm{u} / \partial \mathrm{y}+\partial \mathrm{v} / \partial \mathrm{x}), \text { and } \\
\tau_{\mathrm{yy}} & =[2 \mu(\partial \mathrm{v} / \partial \mathrm{y})-2 / 3 \mu(\partial \mathrm{u} / \partial \mathrm{x}+\partial \mathrm{v} / \partial \mathrm{y})],
\end{aligned}
$$

with $\mu$ being the molecular viscosity. Expressions to $f_{x}$ and $f_{y}$ are given below:

$$
f_{x}=\tau_{x x} u+\tau_{x y} v-q_{x}-q_{v, x} \text { and } f_{y}=\tau_{x y} u+\tau_{y y} v-q_{y}-q_{v y},
$$

where $\mathrm{q}_{\mathrm{x}}$ and $\mathrm{q}_{\mathrm{y}}$ are the Fourier heat flux components and are given by:

$$
\mathrm{q}_{\mathrm{x}}=-\mathrm{k}_{\mathrm{TR}} \partial \mathrm{T} / \partial \mathrm{x} \quad \text { and } \mathrm{q}_{\mathrm{y}}=-\mathrm{k}_{\mathrm{TR}} \partial \mathrm{T} / \partial \mathrm{y},
$$

with $\mathrm{k}_{\mathrm{TR}}$ is the translational/rotational thermal conductivity. The $\mathrm{q}_{\mathrm{v}, \mathrm{x}}$ and $\mathrm{q}_{\mathrm{v}, \mathrm{y}}$ are the vibrational heat flux components and are given by:

$$
\mathrm{q}_{\mathrm{v}, \mathrm{x}}=-\mathrm{k}_{\mathrm{V}} \partial \mathrm{T}_{\mathrm{V}} / \partial \mathrm{x} \text { and } \mathrm{q}_{\mathrm{v}, \mathrm{y}}=-\mathrm{k}_{\mathrm{V}} \partial \mathrm{T}_{\mathrm{V}} / \partial \mathrm{y}
$$

with $\mathrm{k}_{\mathrm{V}}$ being the vibrational thermal conductivity and $\mathrm{T}_{\mathrm{V}}$ is the vibrational temperature, what characterizes this model as of two temperatures: translational/rotational and vibrational. The $\mathrm{Z}$ total energy is defined as:

$$
\mathrm{Z}=\mathrm{c}_{\mathrm{v}, \text { mix }}\left(\mathrm{T}-\mathrm{T}_{\mathrm{REF}}\right)+\Delta \mathrm{h}_{\mathrm{f}, \text { mix }}^{0}+\mathrm{e}_{\mathrm{v}}+0.5\left(\mathrm{u}^{2}+\mathrm{v}^{2}\right)+\mathrm{R}_{\mathrm{b}} \frac{\mathrm{B}^{2}}{2 \rho \mu_{\mathrm{M}}}
$$

with: $\mathrm{T}_{\mathrm{REF}}$ is the reference temperature, and $\Delta \mathrm{h}_{\mathrm{f} \text {,mix }}^{0}$ is the mixture formation enthalpy. The pressure term is given by: 


$$
P=p+R_{b} \frac{B_{x}^{2}+B_{y}^{2}}{2 \mu_{M}}=p+R_{b} \frac{B^{2}}{2 \mu_{M}}
$$

with $\mathrm{p}$ the fluid static pressure. The magnetic force number or pressure number is determined by:

$$
\mathrm{R}_{\mathrm{b}}=\frac{\mathrm{B}_{\infty}^{2}}{\rho_{\infty} \mathrm{V}_{\infty}^{2} \mu_{\mathrm{M}, \infty}}=\frac{\mathrm{B}_{\mathrm{x}, \infty}^{2}+\mathrm{B}_{\mathrm{y}, \infty}^{2}}{\rho_{\infty}\left(\mathrm{u}_{\infty}^{2}+\mathrm{v}_{\infty}^{2}\right) \mu_{\mathrm{M}, \infty}},
$$

where $\mathrm{B}_{\infty}, \rho_{\infty}, \mathrm{V}_{\infty}$, and $\mu_{\mathrm{M}, \infty}$ are freestream flow properties. The laminar Reynolds number is estimated by:

$$
\operatorname{Re}=\frac{\rho_{\infty} \mathrm{V}_{\infty} \mathrm{L}_{\mathrm{REF}}}{\mu_{\infty}},
$$

with $\mathrm{L}_{\mathrm{REF}}$ a characteristic configuration length. The magnetic Reynolds number is calculated by:

$$
\operatorname{Re}_{\sigma}=\mathrm{L}_{\mathrm{REF}} \mathrm{V}_{\infty} \mu_{\mathrm{M}, \infty} \sigma_{\infty}
$$

The components of the Joule heat flux vector, which characterizes the non-ideal formulation, are determined by:

$$
\mathrm{q}_{\mathrm{J}, \mathrm{x}}=-\mathrm{R}_{\mathrm{b}}\left\{\frac{\mathrm{B}_{\mathrm{y}}}{\mu_{\mathrm{M}} \sigma}\left[\frac{\partial}{\partial \mathrm{x}}\left(\frac{\mathrm{B}_{\mathrm{y}}}{\mu_{\mathrm{M}}}\right)-\frac{\partial}{\partial \mathrm{y}}\left(\frac{\mathrm{B}_{\mathrm{x}}}{\mu_{\mathrm{M}}}\right)\right]\right\} \text { and } \mathrm{q}_{\mathrm{J}, \mathrm{y}}=-\mathrm{R}_{\mathrm{b}}\left\{\frac{\mathrm{B}_{\mathrm{x}}}{\mu_{\mathrm{M}} \sigma}\left[\frac{\partial}{\partial \mathrm{y}}\left(\frac{\mathrm{B}_{\mathrm{x}}}{\mu_{\mathrm{M}}}\right)-\frac{\partial}{\partial \mathrm{x}}\left(\frac{\mathrm{B}_{\mathrm{y}}}{\mu_{\mathrm{M}}}\right)\right]\right\} \text {. }
$$

The terms of species diffusion, defined by the Fick law, to a condition of thermal non-equilibrium, are determined by ([30]):

$$
\rho_{\mathrm{s}} \mathrm{v}_{\mathrm{sx}}=-\rho \mathrm{D}_{\mathrm{s}} \frac{\partial \mathrm{Y}_{\mathrm{MF}, \mathrm{s}}}{\partial \mathrm{x}} \text { and } \rho_{\mathrm{s}} \mathrm{v}_{\mathrm{sy}}=-\rho \mathrm{D}_{\mathrm{s}} \frac{\partial \mathrm{Y}_{\mathrm{MF}, \mathrm{s}}}{\partial \mathrm{y}}
$$

with "s" referent to a given species, $\mathrm{Y}_{\mathrm{MF}, \mathrm{s}}$ being the molar fraction of the species, defined as:

$$
\mathrm{Y}_{\mathrm{MF}, \mathrm{s}}=\frac{\rho_{\mathrm{s}} / \mathrm{M}_{\mathrm{s}}}{\sum_{\mathrm{k}=1}^{\mathrm{ns}} \rho_{\mathrm{k}} / \mathrm{M}_{\mathrm{k}}}
$$

and $\mathrm{D}_{\mathrm{s}}$ is the species-effective-diffusion coefficient. The diffusion terms $\phi_{\mathrm{x}}$ and $\phi_{\mathrm{y}}$ which appear in the energy equation are defined by ([31]):

$$
\phi_{\mathrm{x}}=\sum_{\mathrm{s}=1}^{\mathrm{ns}} \rho_{\mathrm{s}} \mathrm{v}_{\mathrm{sx}} \mathrm{h}_{\mathrm{s}} \text { and } \phi_{\mathrm{y}}=\sum_{\mathrm{s}=1}^{\mathrm{ns}} \rho_{\mathrm{s}} \mathrm{v}_{\mathrm{sy}} \mathrm{h}_{\mathrm{s}}
$$

being $h_{s}$ the specific enthalpy (sensible) of the chemical species "s". The molecular diffusion terms calculated at the vibrational temperature, $\phi_{v, x}$ and $\phi_{v, y}$, which appear in the vibrational-internal-energy equation are defined by ([30]): 


$$
\phi_{\mathrm{v}, \mathrm{x}}=\sum_{\mathrm{s}=\mathrm{mol}} \rho_{\mathrm{s}} \mathrm{v}_{\mathrm{sx}} \mathrm{h}_{\mathrm{v}, \mathrm{s}} \text { and } \phi_{\mathrm{v}, \mathrm{y}}=\sum_{\mathrm{s}=\mathrm{mol}} \rho_{\mathrm{s}} \mathrm{v}_{\mathrm{sy}} \mathrm{h}_{\mathrm{v}, \mathrm{s}}
$$

with $\mathrm{h}_{\mathrm{V}, \mathrm{s}}$ being the specific enthalpy (sensible) of the chemical species "s" calculated at the vibrational temperature $\mathrm{T}_{\mathrm{V}}$. The sum of Eq. (18), as also those present in Eq. (4), considers only the molecules of the system, namely: $\mathrm{N}_{2}, \mathrm{O}_{2}, \mathrm{NO}, \mathrm{N}_{2}^{+}, \mathrm{O}_{2}^{+}$and $\mathrm{NO}^{+}$.

\section{Maciel Centered Scheme}

Maciel centered scheme is obtained by arithmetical average between the flux at the left and right states of the interface. Considering the two-dimensional and structured case, the algorithm is divided in three parts, as recommended by [32], each one corresponding to a characteristic flux. The first part takes into account the dynamic part, which considers the Navier-Stokes equations plus the Maxwell equations, the second one takes into account the chemical part, and the third part takes into account the vibrational part. Hence, the discrete-dynamic-convective flux is given by:

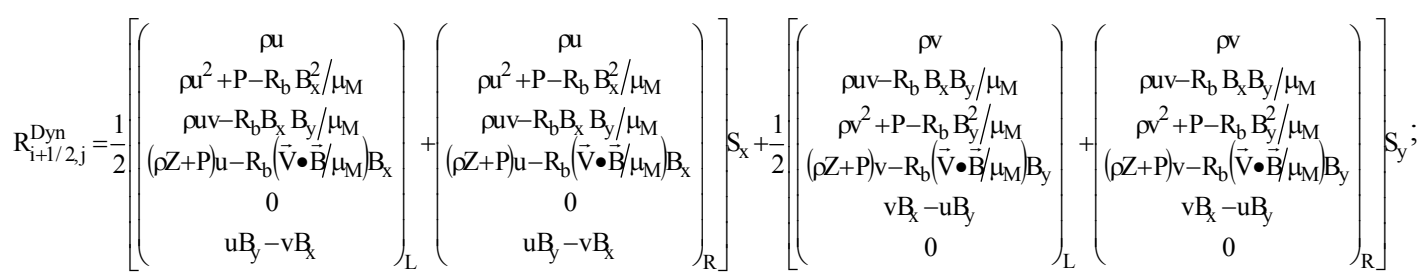

the discrete-chemical-convective flux is defined by:

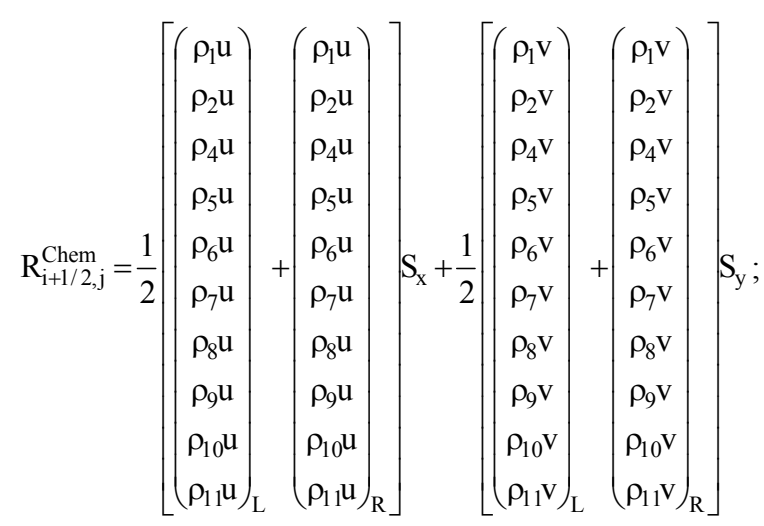

and the discrete-vibrational-convective flux is determined by:

$$
\mathrm{R}_{\mathrm{i}+1 / 2, j}^{\mathrm{Vib}}=\frac{1}{2}\left[\left(\rho \mathrm{e}_{\mathrm{v}} \mathrm{u}\right)_{\mathrm{L}}+\left(\rho \mathrm{e}_{\mathrm{v}} \mathrm{u}\right)_{\mathrm{R}}\right] \mathrm{S}_{\mathrm{x}}+\frac{1}{2}\left[\left(\rho \mathrm{e}_{\mathrm{v}} \mathrm{v}\right)_{\mathrm{L}}+\left(\rho \mathrm{e}_{\mathrm{v}} \mathrm{v}\right)_{\mathrm{R}}\right] \mathrm{S}_{\mathrm{y}}
$$

The viscous formulation follows that of [33], which adopts the Green theorem to calculate primitive variable gradients. The viscous vectors are also obtained by arithmetical average between cell $(\mathrm{i}, \mathrm{j})$ and its neighbors. As was done with the convective terms, there is a need to separate the viscous flux in three parts: dynamical viscous flux, chemical viscous flux and vibrational viscous flux. The dynamical part corresponds to: 


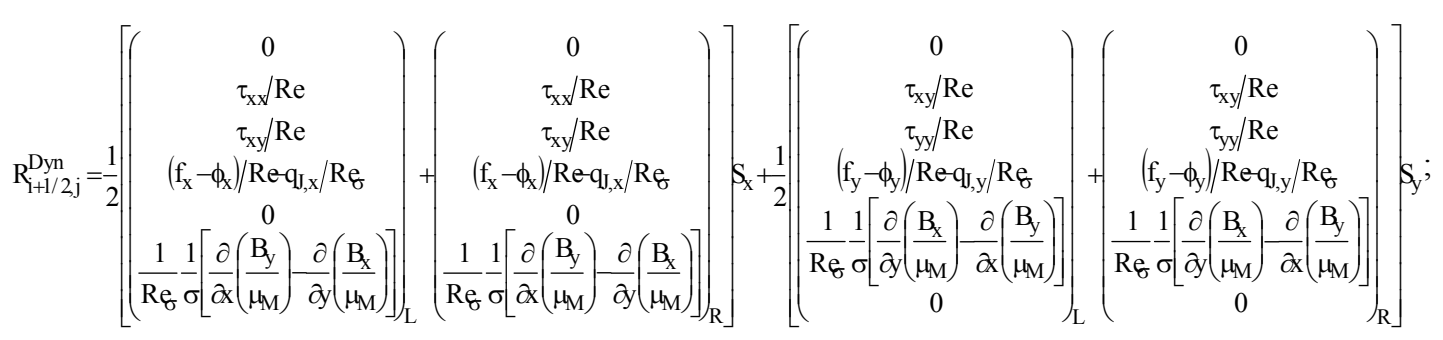

To the chemical part one has:

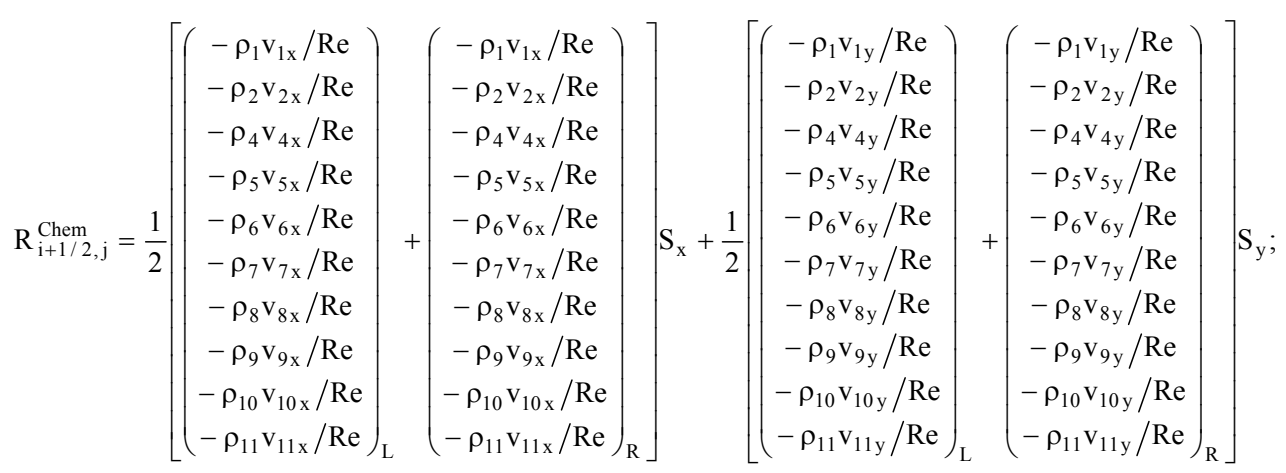

Finally, to the vibrational part:

$$
\mathrm{R}_{\mathrm{i}+1 / 2, \mathrm{j}}^{\mathrm{Vib}}=\frac{1}{2}\left[\left(\frac{-\mathrm{q}_{\mathrm{v}, \mathrm{x}}-\phi_{\mathrm{v}, \mathrm{x}}}{\mathrm{Re}}\right)_{\mathrm{L}}+\left(\frac{-\mathrm{q}_{\mathrm{v}, \mathrm{x}}-\phi_{\mathrm{v}, \mathrm{x}}}{\mathrm{Re}}\right)_{\mathrm{R}}\right] \mathrm{S}_{\mathrm{x}}+\frac{1}{2}\left[\left(\frac{-\mathrm{q}_{\mathrm{v}, \mathrm{y}}-\phi_{\mathrm{v}, \mathrm{y}}}{\mathrm{Re}}\right)_{\mathrm{L}}+\left(\frac{-\mathrm{q}_{\mathrm{v}, \mathrm{y}}-\phi_{\mathrm{v}, \mathrm{y}}}{\mathrm{Re}}\right)_{\mathrm{R}}\right] \mathrm{S}_{\mathrm{y}} .
$$

where $S_{i+1 / 2, j}=\left[\begin{array}{ll}S_{x} & S_{y}\end{array}\right]_{i+1 / 2, j}^{t}$ defines the normal area vector for the surface $(i+1 / 2, j)$. The normal area components $S_{x}$ and $S_{y}$ to each flux interface are given in Table 1. Fig. 1 exhibits the computational cell adopted for the simulations, as well its respective nodes and flux interfaces.

The resultant ordinary differential equation system can be written as:

$$
\mathrm{V}_{\mathrm{i}, \mathrm{j}} \mathrm{dQ}, \mathrm{d} / \mathrm{dt}=-\left(\mathrm{R}_{\mathrm{i}, \mathrm{j}-1 / 2}+\mathrm{R}_{\mathrm{i}+1 / 2, \mathrm{j}}+\mathrm{R}_{\mathrm{i}, \mathrm{j}+1 / 2}+\mathrm{R}_{\mathrm{i}-1 / 2, \mathrm{j}}\right)=-\mathrm{C}_{\mathrm{i}, \mathrm{j}}
$$

where the cell volume is given by:

$$
V_{i, j}=0.5\left(x_{i, j}-x_{i+1, j}\right) y_{i+1, j+1}+\left(x_{i+1, j}-x_{i+1, j+1}\right) y_{i, j}+\left(x_{i+1, j+1}-x_{i, j}\right) y_{i+1, j}\left|+0.5\left(x_{i, j}-x_{i+1, j+1}\right) y_{i, j+1}+\left(x_{i+1, j+1}-x_{i, j+1}\right) y_{i, j}+\left(x_{i, j+1}-x_{i, j}\right) y_{i+1, j+1}\right| .
$$

This centered scheme is second order accurate in space, according to a finite difference discretization, and needs an artificial dissipation operator, $\mathrm{D}$, to guarantee stability in presence of shock waves and background instabilities. Considering this operator, Eq. (25) can be rewritten as:

$$
\mathrm{dQ}_{\mathrm{i}, \mathrm{j}} / \mathrm{dt}=-\left(\mathrm{C}_{\mathrm{i}, \mathrm{j}}-\mathrm{D}_{\mathrm{i}, \mathrm{j}}\right) / \mathrm{V}_{\mathrm{i}, \mathrm{j}},
$$


where $\mathrm{D}$ has the following structure:

$$
\mathrm{D}\left(\mathrm{Q}_{\mathrm{i}, \mathrm{j}}\right)=\mathrm{d}^{(2)}\left(\mathrm{Q}_{\mathrm{i}, \mathrm{j}}\right)-\mathrm{d}^{(4)}\left(\mathrm{Q}_{\mathrm{i}, \mathrm{j}}\right),
$$

with:

$$
\begin{aligned}
& \mathrm{d}^{(2)}=0.5 \varepsilon_{i, j-1 / 2}^{(2)}\left(\mathrm{A}_{\mathrm{i}, \mathrm{j}}+\mathrm{A}_{\mathrm{i}, \mathrm{j}-1}\right)\left(\mathrm{Q}_{\mathrm{i}, \mathrm{j}-1}-\mathrm{Q}_{\mathrm{i}, \mathrm{j}}\right)+0.5 \varepsilon_{\mathrm{i}+1 / 2, \mathrm{j}}^{(2)}\left(\mathrm{A}_{\mathrm{i}, \mathrm{j}}+\mathrm{A}_{\mathrm{i}+1, \mathrm{j}}\right)\left(\mathrm{Q}_{\mathrm{i}+1, \mathrm{j}}-\mathrm{Q}_{\mathrm{i}, \mathrm{j}}\right) \\
& 0.5 \varepsilon_{\mathrm{i}, \mathrm{j}+1 / 2}^{(2)}\left(\mathrm{A}_{\mathrm{i}, \mathrm{j}}+\mathrm{A}_{\mathrm{i}, \mathrm{j}+1}\right)\left(\mathrm{Q}_{\mathrm{i}, \mathrm{j}+1}-\mathrm{Q}_{\mathrm{i}, \mathrm{j}}\right)+0.5 \varepsilon_{\mathrm{i}-1 / 2, \mathrm{j}}^{(2)}\left(\mathrm{A}_{\mathrm{i}, \mathrm{j}}+\mathrm{A}_{\mathrm{i}-1, \mathrm{j}, \mathrm{j}}\right)\left(\mathrm{Q}_{\mathrm{i}-1, \mathrm{j}}-\mathrm{Q}_{\mathrm{i}, \mathrm{j}}\right),
\end{aligned}
$$

named the undivided Laplacian operator, responsible by the numerical stability in presence of shock waves; and

$$
\begin{aligned}
& \mathrm{d}^{(4)}=0.5 \varepsilon_{i, j-1 / 2}^{(4)}\left(\mathrm{A}_{\mathrm{i}, \mathrm{j}}+\mathrm{A}_{\mathrm{i}, \mathrm{j}-1}\right)\left(\nabla^{2} \mathrm{Q}_{\mathrm{i}, \mathrm{j}-1}-\nabla^{2} \mathrm{Q}_{\mathrm{i}, \mathrm{j}}\right)+0.5 \varepsilon_{\mathrm{i}+1 / 2, \mathrm{j}}^{(4)}\left(\mathrm{A}_{\mathrm{i}, \mathrm{j}}+\mathrm{A}_{\mathrm{i}+1, \mathrm{j}}\right)\left(\nabla^{2} \mathrm{Q}_{\mathrm{i}+1, \mathrm{j}}-\nabla^{2} \mathrm{Q}_{\mathrm{i}, \mathrm{j}}\right)+ \\
& 0.5 \varepsilon_{\mathrm{i}, \mathrm{j}+1 / 2}^{(4)}\left(\mathrm{A}_{\mathrm{i}, \mathrm{j}}+\mathrm{A}_{\mathrm{i}, \mathrm{j}+1}\right)\left(\nabla^{2} \mathrm{Q}_{\mathrm{i}, \mathrm{j}+1}-\nabla^{2} \mathrm{Q}_{\mathrm{i}, \mathrm{j}}\right)+0.5 \varepsilon_{\mathrm{i}-1 / 2, \mathrm{j}}^{(4)}\left(\mathrm{A}_{\mathrm{i}, \mathrm{j}}+\mathrm{A}_{\mathrm{i}-1, \mathrm{j}}\right)\left(\nabla^{2} \mathrm{Q}_{\mathrm{i}-1, \mathrm{j}}-\nabla^{2} \mathrm{Q}_{\mathrm{i}, \mathrm{j}}\right),
\end{aligned}
$$

named the bi-harmonic operator, responsible by the background stability (odd-even instabilities, for instance). In this last term,

$$
\nabla^{2} Q_{i, j}=\left(Q_{i, j-1}-Q_{i, j}\right)+\left(Q_{i+1, j}-Q_{i, j}\right)+\left(Q_{i, j+1}-Q_{i, j}\right)+\left(Q_{i-1, j}-Q_{i, j}\right) .
$$

In the $\mathrm{d}^{(4)}$ operator, $\nabla^{2} \mathrm{Q}_{\mathrm{i}, \mathrm{j}}$ is extrapolated from its neighbor cell every time that such one represent an especial boundary layer cell, recognized in the CFD literature as "ghost" cell. The $\varepsilon$ terms are defined, for instance, as:

$$
\varepsilon_{i+1 / 2, j}^{(2)}=K^{(2)} \operatorname{MAX}\left(v_{i+1, j}, v_{i, j}\right) \text { and } \varepsilon_{i+1 / 2, j}^{(4)}=\operatorname{MAX}\left[0,\left(K^{(4)}-\varepsilon_{i+1 / 2, j}^{(2)}\right)\right],
$$

in which:

$$
v_{i, j}=\left(\left|p_{i, j-1}-p_{i, j}\right|+\left|p_{i+1, j}-p_{i, j}\right|+\left|p_{i, j+1}-p_{i, j}\right|+\left|p_{i-1, j}-p_{i, j}\right|\right) /\left(p_{i, j-1}+p_{i+1, j}+p_{i, j+1}+p_{i-1, j}+4 p_{i, j}\right) .
$$

represents a pressure sensor employed to identify regions of high gradients. Each time that a neighbor cell represent a ghost cell, it is assumed that, for instance, $v_{\text {ghost }}=v_{i, j}$. The $A_{i, j}$ terms define the particular artificial dissipation operator. Two models were studied in this work.

\subsection{Artificial dissipation operator of mavriplis / scalar, non-linear, and isotropic model}

In this case, the $A_{i, j}$ terms represent the sum of the contributions of the maximum normal eigenvalue associated to the flux interface of the Euler equations, integrated along each cell face. Based on [20] work, these terms are defined as:

$$
\begin{aligned}
& \mathrm{A}_{\mathrm{i}, \mathrm{j}}=\left[\left|\mathrm{u}_{\mathrm{inn}} \mathrm{S}_{\mathrm{x}}+\mathrm{v}_{\mathrm{int}} \mathrm{S}_{\mathrm{y}}\right|_{\mathrm{i}, \mathrm{j}-1 / 2}+\mathrm{a}_{\mathrm{int}}\left(\mathrm{S}_{\mathrm{x}}^{2}+\mathrm{S}_{\mathrm{y}}^{2}\right)_{\mathrm{i}, \mathrm{j}-1 / 2}^{0.5}\right]+\left[\left|\mathrm{u}_{\mathrm{int}} \mathrm{S}_{\mathrm{x}}+\mathrm{v}_{\mathrm{int}} \mathrm{S}_{\mathrm{y}}\right|_{\mathrm{i}+1 / 2, \mathrm{j}}+\mathrm{a}_{\mathrm{int}}\left(\mathrm{S}_{\mathrm{x}}^{2}+\mathrm{S}_{\mathrm{y}}^{2}\right)_{\mathrm{i}+1 / 2, \mathrm{j}}^{0.5}\right]+ \\
& {\left[\left|\mathrm{u}_{\mathrm{int}} \mathrm{S}_{\mathrm{x}}+\mathrm{v}_{\mathrm{inn}} \mathrm{S}_{\mathrm{y}}\right|_{\mathrm{i}, \mathrm{j}+1 / 2}+\mathrm{a}_{\mathrm{int}}\left(\mathrm{S}_{\mathrm{x}}^{2}+\mathrm{S}_{\mathrm{y}}^{2}\right)_{\mathrm{i}, \mathrm{j}+1 / 2}^{0.5}\right]+\left[\left|\mathrm{u}_{\mathrm{inn}} \mathrm{S}_{\mathrm{x}}+\mathrm{v}_{\mathrm{int}} \mathrm{S}_{\mathrm{y}}\right|_{\mathrm{i}-1 / 2, \mathrm{j}}+\mathrm{a}_{\mathrm{int}}\left(\mathrm{S}_{\mathrm{x}}^{2}+\mathrm{S}_{\mathrm{y}}^{2}\right)_{\mathrm{i}-1 / 2, \mathrm{j}}^{0.5}\right],}
\end{aligned}
$$

where " $\mathrm{a}$ " represents the sound speed and the interface properties are evaluated by arithmetical average. The $\mathrm{K}^{(2)}$ and $\mathrm{K}^{(4)}$ constants have typical values of $1 / 4$ and $3 / 256$, respectively. 


\subsection{Artificial dissipation model of Turkel and Vatsa / scalar, non-linear, and anisotropic model}

The aforementioned artificial dissipation model presents the characteristic of being isotropic. In words, the dissipation introduced artificially in a given coordinate direction to stabilize the scheme weights equally the phenomena originated from all directions, having not a more significant weighting from the particular direction under study. The dissipation is clearly isotropic. The scalar, non-linear and anisotropic artificial dissipation model of [21] aims to provide a numerical attenuation that considers with bigger weight the propagation information effects associated to the characteristic maximum eigenvalue from the coordinate direction under study. Basically, such artificial dissipation model differs from the non-linear, isotropic model of [20] only in the determination of the weighting term of the dissipation operator.

$$
\begin{aligned}
& \mathrm{A}_{\xi}=\bar{\lambda}_{\xi_{i+1 / 2, j}}\left[1+\left(\bar{\lambda}_{\eta} / \bar{\lambda}_{\xi}\right)_{\mathrm{i}+1 / 2, \mathrm{j}}^{0.5}\right] \text { and } \bar{\lambda}_{\xi_{\mathrm{i}+1 / 2, \mathrm{j}}}=\left(\left|\mathrm{un}_{\mathrm{x}}+\mathrm{vn}_{\mathrm{y}}\right|+\mathrm{a}\right)_{\mathrm{i}+1 / 2, \mathrm{j}} \mathrm{S}_{\mathrm{i}+1 / 2, \mathrm{j}} \\
& \mathrm{A}_{\eta}=\bar{\lambda}_{\eta_{\mathrm{i}, j+1 / 2}}\left[1+\left(\bar{\lambda}_{\xi} / \bar{\lambda}_{\eta}\right)_{\mathrm{i}, \mathrm{j}+1 / 2}^{0.5}\right] \text { and } \bar{\lambda}_{\eta_{\mathrm{i}, \mathrm{j}+1 / 2}}=\left(\left|\mathrm{un}_{\mathrm{x}}+\mathrm{vn}_{\mathrm{y}}\right|+\mathrm{a}\right)_{\mathrm{i}, \mathrm{j}+1 / 2} \mathrm{~S}_{\mathrm{i}, \mathrm{j}+1 / 2} .
\end{aligned}
$$

To this artificial dissipation model, the recommended values to $\mathrm{K}^{(2)}$ and $\mathrm{K}^{(4)}$ by [21] are $1 / 2$ and $1 / 64$, respectively.

\section{Time Integration}

Two methods of time integration were studied in this work: Euler Backward, and Middle Point. They are described by the equations below.

\subsection{Euler backward}

This method is first-order accurate in time, to the three types of complete flux. To the dynamic part, this method can be represented in general form by:

$$
Q_{i, j}^{(n+1)}=Q_{i, j}^{(n)}-\left(\Delta t_{i, j} / V_{i, j}\right) \times\left[C\left(Q_{i, j}^{(n)}\right)-D\left(Q_{i, j}^{(n)}\right)\right],
$$

to the chemical part, it can be represented in general form by:

$$
\mathrm{Q}_{\mathrm{i}, \mathrm{j}}^{(\mathrm{n}+1)}=\mathrm{Q}_{\mathrm{i}, \mathrm{j}}^{(\mathrm{n})}-\Delta \mathrm{t}_{\mathrm{i}, \mathrm{j}} \times\left\{\left[\mathrm{C}\left(\mathrm{Q}_{\mathrm{i}, \mathrm{j}}^{(\mathrm{n})}\right)-\mathrm{D}\left(\mathrm{Q}_{\mathrm{i}, \mathrm{j}}^{(\mathrm{n})}\right)\right] / \mathrm{V}_{\mathrm{i}, \mathrm{j}}-\mathrm{S}_{\mathrm{C}}\left(\mathrm{Q}_{\mathrm{i}, \mathrm{j}}^{(\mathrm{n})}\right)\right\},
$$

where the chemical source term $\mathrm{S}_{\mathrm{C}}$ is calculated with the temperature $\mathrm{T}_{\text {rrc }}$ (reaction rate controlling temperature), defined in [28-29]. Finally, to the vibrational part:

$$
\left.Q_{i, j}^{(n+1)}=Q_{i, j}^{(n)}-\Delta t_{i, j} \times\left\{C\left(Q_{i, j}^{(n)}\right)-D\left(Q_{i, j}^{(n)}\right)\right] / V_{i, j}-S_{V}\left(Q_{i, j}^{(n)}\right)\right\},
$$

in which:

$$
\mathrm{S}_{\mathrm{V}}=\sum_{\mathrm{s}=\mathrm{mol}} \mathrm{q}_{\mathrm{T}-\mathrm{V}, \mathrm{s}}+\sum_{\mathrm{s}=\mathrm{mol}} \mathrm{S}_{\mathrm{C}, \mathrm{s}} \mathrm{e}_{\mathrm{v}, \mathrm{s}}
$$


where $\mathrm{q}_{\mathrm{T}-\mathrm{V}}$ is the heat flux due to translational-vibrational relaxation, defined in [28-29].

\subsection{Middle point}

This method is a second-order, two-stage Runge-Kutta one, to the three types of complete flux. To the dynamic part, this method can be represented in general form by:

$$
\begin{aligned}
& \mathrm{Q}_{\mathrm{i}, \mathrm{j}}^{(0)}=\mathrm{Q}_{\mathrm{i}, \mathrm{j}}^{\mathrm{n}} \\
& \mathrm{Q}_{\mathrm{i}, \mathrm{j}}^{(\mathrm{k})}=\mathrm{Q}_{\mathrm{i}, \mathrm{j}}^{(0)}+\mathrm{\alpha}_{\mathrm{k}}\left(\Delta \mathrm{t}_{\mathrm{i}, \mathrm{j}} / \mathrm{V}_{\mathrm{i}, \mathrm{j}}\right)\left[\mathrm{C}\left(\mathrm{Q}_{\mathrm{i}, \mathrm{j}}^{(\mathrm{k}-1)}\right)-\mathrm{D}\left(\mathrm{Q}_{\mathrm{i}, \mathrm{j}}^{(\mathrm{k}-1)}\right)\right], \\
& \mathrm{Q}_{\mathrm{i}, \mathrm{j}}^{\mathrm{n}+1}=\mathrm{Q}_{\mathrm{i}, \mathrm{j}}^{(\mathrm{k})}
\end{aligned}
$$

to the chemical part, it can be represented in general form by:

$$
\begin{aligned}
& Q_{i, j}^{(0)}=Q_{i, j}^{n} \\
& \left.Q_{i, j}^{(k)}=Q_{i, j}^{(0)}+\alpha_{k} \Delta t_{i, j}\left\{C\left(Q_{i, j}^{(k-1)}\right)-D\left(Q_{i, j}^{(k-1)}\right)\right] / V_{i, j}-S_{C}\left(Q_{i, j}^{k-1}\right)\right\}, \\
& Q_{i, j}^{n+1}=Q_{i, j}^{(k)}
\end{aligned}
$$

and to the vibrational part:

$$
\begin{aligned}
& \mathrm{Q}_{\mathrm{i}, \mathrm{j}}^{(0)}=\mathrm{Q}_{\mathrm{i}, \mathrm{j}}^{\mathrm{n}} \\
& \left.\mathrm{Q}_{\mathrm{i}, \mathrm{j}}^{(\mathrm{k})}=\mathrm{Q}_{\mathrm{i}, \mathrm{j}}^{(0)}+\alpha_{\mathrm{k}} \Delta \mathrm{t}_{\mathrm{i}, \mathrm{j}}\left[\mathrm{C}\left(\mathrm{Q}_{\mathrm{i}, \mathrm{j}}^{(\mathrm{k}-1)}\right)-\mathrm{D}\left(\mathrm{Q}_{\mathrm{i}, \mathrm{j}}^{(\mathrm{k}-1)}\right)\right] / \mathrm{V}_{\mathrm{i}, \mathrm{j}}-\mathrm{S}_{\mathrm{V}}\left(\mathrm{Q}_{\mathrm{i}, \mathrm{j}}^{\mathrm{k}-1}\right)\right\}, \\
& \mathrm{Q}_{\mathrm{i}, \mathrm{j}}^{\mathrm{n}+1}=\mathrm{Q}_{\mathrm{i}, \mathrm{j}}^{(\mathrm{k})}
\end{aligned}
$$

where the $\alpha$ values of each stage are: $\alpha_{1}=1 / 2$ and $\alpha_{2}=1.0$.

\section{Spatially Variable Time Step}

The spatially variable time step has proved efficient gains in terms of convergence acceleration, as proved by [22-23]. Initially, the parameter $\sigma$ is determined, where:

$$
\sigma_{\mathrm{s}}=\frac{\mathrm{c}_{\mathrm{s}}}{\mathrm{M}_{\mathrm{s}}} \quad \text { and } \quad \sigma=\sum_{\mathrm{s}=1}^{\mathrm{N}} \sigma_{\mathrm{s}}
$$

with $\mathrm{c}_{\mathrm{s}}$ being the mass fraction and $\mathrm{M}_{\mathrm{s}}$ the molecular weight. The total specific heat at constant volume due to translation is defined as:

$$
\mathrm{c}_{\mathrm{V}, \mathrm{T}}=\sum_{\mathrm{s}=1}^{\mathrm{N}} \sigma_{\mathrm{s}} \mathrm{c}_{\mathrm{V}, \mathrm{T}, \mathrm{s}},
$$

where, for each gas constituent of the eleven (11) species chemical model, the specific heat at constant volume, based on the kinetic theory of gases ([34]), is defined by

$$
\mathrm{c}_{\mathrm{V}, \mathrm{T}, \mathrm{N}}=\frac{3}{2} \mathrm{R}_{\mathrm{N}}, \mathrm{c}_{\mathrm{V}, \mathrm{T}, \mathrm{O}}=\frac{3}{2} \mathrm{R}_{\mathrm{O}}, \mathrm{c}_{\mathrm{V}, \mathrm{T}, \mathrm{N}_{2}}=\frac{5}{2} \mathrm{R}_{\mathrm{N}_{2}}, \mathrm{c}_{\mathrm{V}, \mathrm{T}, \mathrm{O}_{2}}=\frac{5}{2} \mathrm{R}_{\mathrm{O}_{2}}, \mathrm{c}_{\mathrm{V}, \mathrm{T}, \mathrm{NO}}=\frac{5}{2} \mathrm{R}_{\mathrm{NO}}
$$




$$
\begin{aligned}
& \mathrm{c}_{\mathrm{V}, \mathrm{T}, \mathrm{N}^{+}}=\frac{3}{2} \mathrm{R}_{\mathrm{N}^{+}}, \mathrm{c}_{\mathrm{V}, \mathrm{T}, \mathrm{O}^{+}}=\frac{3}{2} \mathrm{R}_{\mathrm{O}^{+}}, \mathrm{c}_{\mathrm{V}, \mathrm{T}, \mathrm{N}_{2}^{+}}=\frac{5}{2} \mathrm{R}_{\mathrm{N}_{2}^{+}}, \mathrm{c}_{\mathrm{V}, \mathrm{T}, \mathrm{O}_{2}^{+}}=\frac{5}{2} \mathrm{R}_{\mathrm{O}_{2}^{+}} ; \\
& \mathrm{c}_{\mathrm{V}, \mathrm{T}, \mathrm{NO}^{+}}=\frac{5}{2} \mathrm{R}_{\mathrm{NO}^{+}}, \mathrm{c}_{\mathrm{V}, \mathrm{T}, \mathrm{e}^{-}}=\frac{3}{2} \mathrm{R}_{\mathrm{e}^{-}},
\end{aligned}
$$

being $\mathrm{R}_{\mathrm{s}}$ the specific gas constant. The total pressure of the gaseous mixture is determined by Dalton law, which indicates that the total pressure of the gas is the sum of the partial pressure of each constituent gas, resulting in:

$$
\mathrm{p}_{\mathrm{s}}=\mathrm{c}_{\mathrm{s}} \rho \mathrm{R}_{\mathrm{s}} \mathrm{T} \quad \text { and } \mathrm{p}=\sum_{\mathrm{s}=1}^{\mathrm{N}} \mathrm{p}_{\mathrm{s}}
$$

The speed of sound to a reactive mixture can be determined by:

$$
\mathrm{a}=\sqrt{\frac{(1+\beta) \mathrm{p}}{\rho}}
$$

where $\beta=\frac{R_{u n i v} \sigma}{c_{V, T}}$, with $R_{\text {univ }}=1.987 \mathrm{cal} /(\mathrm{g}-\mathrm{mol} . \mathrm{K})$. Finally, the spatially variable time step is defined from the CFL definition:

$$
\Delta \mathrm{t}_{\mathrm{i}, \mathrm{j}}=\frac{\operatorname{CFL} \Delta \mathrm{s}_{\mathrm{i}, \mathrm{j}}}{\sqrt{\mathrm{u}_{\mathrm{i}, \mathrm{j}}^{2}+\mathrm{v}_{\mathrm{i}, \mathrm{j}}^{2}}+\mathrm{a}_{\mathrm{i}, \mathrm{j}}},
$$

where $\Delta \mathrm{s}_{\mathrm{i}, \mathrm{j}}$ is the characteristic length of each cell (defined between the minimum cell side length and the minimum centroid distance between each cell and its neighbors).

\section{Dimensionless, Initial and Boundary Conditions}

\subsection{Dimensionless}

The dimensionless employed to the reactive equations consisted in: $R_{s}$ is dimensionless by $a_{\text {char }}$, where $\mathrm{a}_{\text {char }}=\sqrt{\gamma \mathrm{p}_{\infty} / \rho_{\infty}} ; \mathrm{c}_{\mathrm{v}}$ is dimensionless by $\mathrm{a}_{\text {char }} ; \mathrm{h}_{\mathrm{s}}$ and $\Delta \mathrm{h}_{\mathrm{s}}^{0}$ are dimensionless by $\mathrm{a}_{\text {char }}^{2} ; \mathrm{T}$ and $\mathrm{Tv}$, translational/rotational temperature and vibrational temperature, respectively, are dimensionless by $\mathrm{a}_{\text {char }} ; \rho_{\mathrm{s}}$ and $\rho$ are dimensionless by $\rho_{\infty} ; \mathrm{u}$ and $\mathrm{v}$ are dimensionless by $\mathrm{a}_{\text {char }} ; \mu$ is dimensionless by $\mu_{\infty} ; \mathrm{D}$, diffusion coefficient, dimensionless by $\mathrm{a}_{\text {char }}^{2} \mathrm{dt}_{\text {char, where }} \mathrm{dt}_{\text {char }}$ is the minimum time step calculated in the computational domain at the first iteration; $\dot{\omega}$ is dimensionless by $\rho_{\infty} \times 10^{-3} / \mathrm{dt}_{\text {char }} ; \mathrm{e}_{\mathrm{v}}$ is dimensionless by $\mathrm{a}_{\text {char }}^{2} ; \mathrm{p}$ is dimensionless by $\rho_{\infty} \mathrm{a}_{\text {char }}^{2} ; \tau_{\mathrm{s}}$, relaxation time, is dimensionless by $\mathrm{dt}_{\text {char. }}$ To the Maxwell equations: the $\mathrm{B}_{\mathrm{x}}$ and $\mathrm{B}_{\mathrm{y}}$ Cartesian components of the magnetic field dimensionless by $\mathrm{B}_{\infty}$; the magnetic permeability of the mean is dimensionless by $\mu_{\mathrm{M}, \infty}$; and the electric conductivity is dimensionless by $\sigma_{\infty}$.

\subsection{Initial condition}

The initial conditions to this problem, for an eleven species chemical model, and the actuation of a magnetic field, are presented in Tab. 2. The Reynolds number is obtained from data of [35]. 


\subsection{Boundary conditions}

The boundary conditions are basically of three types: solid wall, entrance, and exit, implemented in ghost cells.

Wall Condition: In the inviscid case, this condition imposes the flow tangency at wall. This condition is satisfied considering the velocity component tangent to the wall relative to the ghost cell as equal to the respective component of the real neighbor cell. At the same time, the velocity component normal to the wall relative to the ghost cell is equaled to the negative of the corresponding component of the real neighbor cell. This procedure leads to a system of equations which results in:

$$
\mathrm{u}_{\mathrm{g}}=\left(\mathrm{n}_{\mathrm{y}}^{2}-\mathrm{n}_{\mathrm{x}}^{2}\right) \mathrm{u}_{\mathrm{r}}+\left(-2 \mathrm{n}_{\mathrm{x}} \mathrm{n}_{\mathrm{y}}\right) \mathrm{v}_{\mathrm{r}} \quad \text { and } \quad \mathrm{v}_{\mathrm{g}}=\left(-2 \mathrm{n}_{\mathrm{x}} \mathrm{n}_{\mathrm{y}}\right) \mathrm{u}_{\mathrm{r}}+\left(\mathrm{n}_{\mathrm{x}}^{2}-\mathrm{n}_{\mathrm{y}}^{2}\right) \mathrm{v}_{\mathrm{r}} \text {, }
$$

where " $\mathrm{g}$ " indicates ghost cell properties and " $\mathrm{r}$ " indicates real cell properties. In the viscous case, the nonslip condition is enforced. Therefore, the tangent velocity component of the ghost volume at wall has the same magnitude as the respective velocity component of its real neighbor cell, but opposite signal. In the same way, the normal velocity component of the ghost volume at wall is equal in value, but opposite in signal, to the respective velocity component of its real neighbor cell. It results in:

$$
\mathrm{u}_{\mathrm{g}}=-\mathrm{u}_{\mathrm{r}} \quad \text { and } \quad \mathrm{v}_{\mathrm{g}}=-\mathrm{v}_{\mathrm{r}} \text {. }
$$

The normal pressure gradient of the fluid at the wall is assumed to be equal to zero according to an inviscid formulation or a boundary-layer like condition. The same hypothesis is applied for the normal temperature gradient at the wall, assuming an adiabatic wall.

From the above considerations, density and translational/rotational temperature are extrapolated from the respective values of its real neighbor volume (zero order extrapolation). The total vibrational internal energy is also extrapolated.

With the mixture species mass fractions and with the values of the respective specific heats at constant volume, it is possible to obtain the mixture specific heat at constant volume. The mixture formation enthalpy is extrapolated from the real cell. The Cartesian components of the induced magnetic field at the wall to the ghost cells are fixed with their initial values. The magnetic permeability is considered constant with its initial value. The mixture total energy to the ghost cell is calculated by:

$$
\mathrm{Z}_{\mathrm{g}}=\mathrm{Cv}_{\text {mixt, }}\left(\mathrm{T}_{\mathrm{tr}, \mathrm{g}}-\mathrm{T}_{\mathrm{REF}}\right)+\Delta \mathrm{h}_{\text {mixt,g }}^{0}+\mathrm{e}_{\mathrm{v}, \mathrm{dim}, \mathrm{g}}+0.5\left(\mathrm{u}_{\mathrm{g}}^{2}+\mathrm{v}_{\mathrm{g}}^{2}\right)+\mathrm{R}_{\mathrm{b}}\left(\mathrm{B}_{\mathrm{x}, \mathrm{g}}^{2}+\mathrm{B}_{\mathrm{y}, \mathrm{g}}^{2}\right) /\left(2 \mu_{\mathrm{M}, \mathrm{g}} \rho_{\mathrm{g}}\right),
$$

To the species density, the non-catalytic condition is imposed, what corresponds to zero order extrapolation from the real cell. The vibrational internal energy is also extrapolated.

Entrance Condition: It is divided in two flow regimes:

(a) Subsonic flow: Five properties are specified and one extrapolated in the boundary conditions of the dynamic part of the algorithm. This approach is based on information propagation analysis along characteristic directions in the calculation domain ([36]). In other words, for subsonic flow, five characteristics propagate information point into the computational domain. Thus five flow properties must be fixed at the inlet plane. Just one characteristic line allows information to travel upstream. So, one flow variable must be extrapolated from the interior grid to the inlet boundary. The total energy was the extrapolated variable from the real neighbor volumes, for the studied problem. Density, velocity components, and the induced magnetic field components adopted values of freestream flow. To the chemical part, ten information propagate upstream because it is assumed 
that all ten equations are conducted by the eigenvalue " $\left(\mathrm{q}_{\mathrm{n}}-\mathrm{a}\right)$ ". In the subsonic flow, all eigenvalues are negative and the information should be extrapolated. In the same reasoning to the chemical boundary conditions, the vibrational-internal-energy equation is dictated by the " $\left(\mathrm{q}_{\mathrm{n}}-\mathrm{a}\right)$ " eigenvalue and, in the subsonic region, its value is negative. Hence, the vibrational internal energy should be extrapolated.

(b) Supersonic flow: In this case no information travels upstream; therefore all variables are fixed with their of freestream values.

Exit Condition: It is also divided in two flow regimes:

(a) Subsonic flow: Five characteristics propagate information outward the computational domain. Hence, the associated variables should be extrapolated from interior information. The characteristic direction associated to the " $\left(\mathrm{q}_{\mathrm{n}}-\mathrm{a}\right)$ " velocity should be specified because it points inward to the computational domain ([36]). In this case, the ghost volume total energy is specified from its initial value. Density, velocity components, and the induced magnetic field components are extrapolated. To the chemical part, the eigenvalue " $\left(\mathrm{q}_{\mathrm{n}}-\mathrm{a}\right)$ " is again negative and the characteristics are always flowing into the computational domain. Hence, the ten chemical species under study should have their densities fixed by their freestream values. In the same reasoning, the internal vibrational energy should have their value prescribed by its initial value due to the eigenvalue " $\left(\mathrm{q}_{\mathrm{n}}-\mathrm{a}\right)$ " be negative.

(b) Supersonic flow: All variables are extrapolated from interior grid cells, as no flow information can make its way upstream. In other words, nothing can be fixed.

\section{Physical Problem and Meshes}

One physical problem is studied in this work: the blunt body problem. The geometry under study is a blunt body with $1.0 \mathrm{~m}$ of nose ratio and parallel rectilinear walls. The far field is located at 20.0 times the nose ratio in relation to the configuration nose.

Fig. 2 shows the inviscid mesh used to the blunt body problem. This mesh is composed of 2,548 rectangular cells and 2,650 nodes. This mesh is equivalent in finite differences to a one of 53x50 points. The same mesh with, however, an exponential stretching of $5.0 \%$ in the $\eta$ direction, was used to the viscous simulations, Fig. 3. A "O" mesh is taken as the base to construct such meshes. No smoothing is used in this mesh generation process, being this one constructed in Cartesian coordinates.

\section{Results}

Tests were performed in a Core i7 processor of $2.1 \mathrm{GHz}$ and $8.0 \mathrm{Gbytes}$ of RAM microcomputer, in a Windows 7.0 environment. Four (4) orders of reduction of the maximum residual in the field were considered to obtain a converged solution. The residual was defined as the value of the discretized conservation equation. In the dynamic part, such definition results in:

$$
\text { Residual }=-\Delta t_{i, j} / V_{i, j} \times\left(C_{i, j}-D_{i, j}\right) \text {. }
$$

The attack angle was adopted equal to zero.

\subsection{Inviscid results}

Euler Backward: Figs. 4 and 5 show the pressure contours obtained by the Maciel scheme as using the [20] artificial dissipation model. Fig. 4 is related to the [24] chemical model, whereas Fig. 5 is related to the [25] 
chemical model. The value of the pressure peak is around 92.38 unities to the [24] chemical model, whereas is around 92.91 unities to the [25] chemical model. Good symmetry properties are observed in both figures. The normal shock wave is well captured by the numerical algorithm.

Figs. 6 and 7 present the $\mathrm{N}_{2}$ mass fraction contours obtained by the Maciel scheme, employing the [20] artificial dissipation model, for the [24] and [25] chemical models, respectively. No pre-shock oscillations are observed in both figures. The $\mathrm{N}_{2}$ mass fraction contours generated by the [24] and [25] chemical models present good dissociation of this species, where the maximum dissociation has the value 0.7349 due to [25] chemical model. Good symmetry characteristics are observed in both solutions.

Figs. 8 and 9 present the contours of the $\mathrm{B}_{\mathrm{x}}$ component of the magnetic field obtained by the Maciel scheme as using the [20] artificial dissipation operator for the [24] and [25] chemical models, respectively. Reasonable characteristics of symmetry are observed with the [20] operator solution, as can be seen by the legend.

Figs. 10 and 11 show the magnetic induction lines captured by the Maciel scheme as using the [20] dissipation operators for the [24] and [25] chemical models, respectively. As expected, the induction lines surround the blunt body configuration. This behavior is described in [27] and verified in the present simulations. Good symmetry characteristics are observed in both figures.

Figs. 12 and 13 show the pressure contours obtained with the Maciel scheme as using the [21] dissipation operator for the [24] and [25] chemical models, respectively. The [25] solution is more strength than the [24] solution, reaching a more severe value to the stagnation pressure. The former reaches the value of 100.81 unities, whereas the latter reaches the value of 100.19 unities. Good symmetry properties are observed in both solutions. The shock wave is well captured without pressure oscillations.

Figs. 14 and 15 exhibit the $\mathrm{N}_{2}$ mass fraction contours obtained with the Maciel scheme as using the [21] dissipation model for the [24] and [25] chemical models, respectively. Good $\mathrm{N}_{2}$ dissociation is observed in both solutions, with slightly increase for the [25] chemical model. Good symmetry properties are observed.

Figs. 16 and 17 show the $\mathrm{B}_{\mathrm{x}}$ component contours generated by the Maciel scheme as using the [21] dissipation model for the [24] and [25] chemical models, respectively. Both solutions present good results in terms of symmetry, better than the solutions with the [20] dissipation model. It can be observed in both legends.

Figs. 18 and 19 exhibit the magnetic induction lines captured by the Maciel scheme as using the [21] dissipation model for the [24] and [25] chemical models, respectively. The curves surround the blunt body, as expected. Good symmetry properties of the induction magnetic field are observed. The induction lines generated by the [24] and [25] chemical models using the [21] dissipation model are more curved than the respective ones using the [20] dissipation model, indicating less dissipation of the former.

Middle Point: Figs. 20 and 21 show the pressure contours calculated by the Maciel scheme as using the [20] dissipation model for the [24] and [25] chemical models, respectively. Good symmetry properties are observed in both solutions. The pressure field calculated with the [25] chemical model is more strength than the respective one calculated with the [24] chemical model, as occurred in Figs. 4 and 5. No pre-shock oscillations are observed.

Figs. 22 and 23 exhibit the $\mathrm{N}_{2}$ mass fraction contours obtained by the Maciel scheme as using the [20] artificial dissipation model for the [24] and [25] chemical models, respectively. The mass fraction field associated with the [25] chemical model is slightly more intense than the respective one associated with the [24] chemical model. The maximum dissociation reaches the value of 0.7349 , the same of the Euler Backward time integration. 
Figs. 24 and 25 show the contours of the $\mathrm{B}_{\mathrm{x}}$ component of the magnetic field obtained by the Maciel scheme as using the [20] dissipation model for the [24] and [25] chemical models, respectively. Reasonable symmetry properties are observed in both solutions, as observed by the legend.

Figs. 26 and 27 present the magnetic induction lines captured by the Maciel scheme as using the [20] dissipation operator for the [24] and [25] chemical models, respectively. As expected, the induction lines surround the blunt body configuration. This behavior is described in [27] for the perfect gas formulation and verified in the present reactive simulation. Good symmetry characteristics are observed in both figures.

Figs. 28 and 29 show the pressure contours generated by the Maciel scheme as using the [21] dissipation model for the [24] and [25] chemical models, respectively. The pressure field calculated with the [24] chemical model is smaller than the respective one calculated with the [25] chemical model. No pre-shock oscillations are observed.

Figs. 30 and 31 exhibit the $\mathrm{N}_{2}$ mass fraction contours generated by the Maciel scheme as using the [21] dissipation model for the [24] and [25] chemical models, respectively. Good dissociation is observed in both figures, with the maximum dissociation captured by the [25] chemical model with the value of 0.7347 . Good symmetry characteristics are observed.

Figs. 32 and 33 present the $B_{x}$ component contours obtained by the Maciel scheme as using the [21] dissipation model for the [24] and [25] chemical models, respectively. Good symmetry properties are observed as seen in the legends. No pre-shock oscillations are observed.

Figs. 34 and 35 show the magnetic induction lines obtained by the Maciel scheme as using the [21] dissipation model for the [24] and [25] chemical models, respectively. Good symmetry aspects are observed in these magnetic induction lines in relation to the blunt body symmetry line. Curves more curved than the [20] solutions are observed.

As conclusion of the inviscid case, the [25] chemical model presents the best values to the stagnation pressure than the [24] chemical model, as using both artificial dissipation models, being more severe with the [21] dissipation model. Moreover, the [21] dissipation model presents more curved induction lines in the field close to the blunt body, indicating minor dissipation aspects in its application.

\subsection{Viscous results}

Euler Backward: Figs. 36 and 37 show the pressure contours obtained by the Maciel numerical scheme as using the [20] dissipation model for the [24] and [25] chemical models, respectively. Good symmetry properties are observed in both solutions. The stagnation pressure estimated by the [24] chemical model, 155.26 unities, is bigger than the respective one estimated by the [25] chemical model, 155.14 unities. This behavior is opposed to that observed in the inviscid case and, due to its more realistic conditions, is the most correct. No pre-shock oscillations are observed and good symmetry aspects are observed.

Figs. 38 and 39 exhibit $\mathrm{N}_{2}$ mass fraction contours obtained by the Maciel algorithm as using the [20] artificial dissipation model for the [24] and [25] chemical models, respectively. In this viscous case, minor dissociation is observed in both solutions, with its maximum value reaching 0.7332 for the [25] chemical model. Good symmetry properties are observed. No pre-shock oscillations are noted in both solutions. The shock wave behaves normally: normal shock at the stagnation line, oblique shock waves close to the body, and Mach wave far from the body.

Figs. 40 and 41 present the $B_{x}$ component of the magnetic field contours obtained by the Maciel scheme as using the [20] artificial dissipation operator for the [24] and [25] chemical models, respectively. Both solutions present problems of asymmetry as observed in the legends. 
Figs. 42 and 43 show the magnetic induction lines captured by the Maciel scheme as using the [20] artificial dissipation model for the [24] and [25] chemical models, respectively. Reasonable behavior and reasonable symmetry properties are observed in both solutions.

Figs. 44 and 45 exhibit the pressure contours generated by the Maciel scheme as using the [21] dissipation model for the [24] and [25] chemical models, respectively. The most severe pressure field is again captured by the [24] chemical model for this viscous case. The former presents the value of 154.89 unities, whereas the latter presents the value of 154.84 unities. Good symmetry properties are observed and not pre-shock oscillations are noted.

Figs. 46 and 47 present the $\mathrm{N}_{2}$ mass fraction contours obtained by the Maciel scheme as using the [21] dissipation model for the [24] and [25] chemical models, respectively. Good dissociations are observed, although inferior to the respective ones calculated in the inviscid case. Good symmetry properties are observed in both figures.

Figs. 48 and 49 show the $B_{x}$ component contours captured by the Maciel scheme as using the [21] dissipation operator for the [24] and [25] chemical models, respectively. Good symmetry aspects are observed, better than the respective ones obtained by the inviscid case.

Figs. 50 and 51 exhibit the magnetic induction lines generated by the Maciel scheme as using the [21] artificial dissipation model for the [24] and [25] chemical models, respectively. Good symmetry aspects are observed, with the induction lines more curved, indicating less dissipative affects with this dissipation model.

Middle Point: Figs. 52 and 53 present the pressure contours obtained by the Maciel scheme employing the [20] dissipation model for the [24] and [25] chemical models, respectively. Good symmetry properties are observed. The stagnation pressure associated with the [24] chemical model is more strength than the respective one of the [25] chemical model. Solutions without pressure oscillations are observed.

Figs. 54 and 55 exhibit the $\mathrm{N}_{2}$ mass fraction contours obtained by the Maciel scheme as using the [20] dissipation model for the [24] and [25] chemical models, respectively. Both solutions present good dissociation of $\mathrm{N}_{2}$, although inferior to that observed in the respective inviscid case. In the inviscid case, the maximum dissociation reaches the value of 0.7349 , whereas in the viscous case its maximum value is 0.7332. Good symmetry properties and good capture of the shock wave are observed. No pre-shock oscillations are noted in both fields.

Figs. 56 and 57 show the $\mathrm{B}_{\mathrm{x}}$ component of the magnetic field contours captured by the Maciel algorithm as using the [20] artificial dissipation operator for the [24] and [25] chemical models, respectively. Reasonable symmetry aspects are observed, as can be confirmed by the legend values.

Figs. 58 and 59 exhibit the magnetic induction lines captured by the Maciel scheme as using the [20] dissipation model for the [24] and [25] chemical models, respectively. The induction lines are more symmetrical, present a better behavior, than the respective inviscid case.

Figs. 60 and 61 show the pressure contours obtained by the Maciel numerical scheme as using the [21] artificial dissipation model for the [24] and [25] chemical models, respectively. The stagnation pressure calculated with the [24] chemical model, 154.89 unities, is bigger than the respective one calculated with the [25] chemical model, 154.84 unities. Good symmetry properties are observed. The shock wave is well captured by the Maciel algorithm as using any of the chemical models and any of the artificial dissipation operators.

Figs. 62 and 63 exhibit the $\mathrm{N}_{2}$ mass fraction contours obtained by the Maciel algorithm as using the [21] dissipation model for the [24] and [25] chemical models, respectively. Again, good dissociation is observed 
in the field, although inferior to that observed in the inviscid case. Good symmetry properties are observed in both figures.

Figs. 64 and 65 present the $\mathrm{B}_{\mathrm{x}}$ component of the magnetic field contours generated by the Maciel algorithm as using the [21] dissipation model for the [24] and [25] chemical models, respectively. As can be observed, symmetry properties are better observed in the viscous solution, as noted in terms of contour curves as in terms of the legends.

Figs. 66 and 67 show the magnetic induced lines captured by the Maciel scheme as using the [21] artificial dissipation model for the [24] and [25] chemical models, respectively. Better symmetry aspects and behavior are observed in the solution obtained with [21] dissipation model. More curved induction lines are observed in the solution with the [21] operator, indicating that minor dissipation is in use.

As conclusion of the viscous case, the [24] chemical model presents the best values to the stagnation pressure than the [25] chemical model, as using both artificial dissipation models, being more severe with the [20] dissipation model, opposed to the behavior observed in the inviscid case. As the Navier-Stokes equations coupled with the Maxwell equations are the most realistic formulation, these solutions are the most correct. Finally, the [21] dissipation model presents more curved induction lines in the field close to the blunt body, indicating minor dissipation aspects in its application.

\subsection{Shock-standoff distance, drag coefficient, and temperature peak}

For this study, the Maciel scheme was applied to the [24] chemical model, using the [20] dissipation model, in the inviscid case, due to its good solution quality, and using the Euler Backward to march in time.

Fig. 68 exhibits the pressure along the stagnation line versus the stagnation line $\mathrm{x}$ coordinate. It is possible to note that with the variation of the magnetic field intensity, no alteration in the shock position is observed. It is opposed to the observed in the perfect gas formulation (see [27]).

Table 3 shows the shock-standoff distance measured in relation to the blunt body nose. As can be observed, the actuation of a magnetic field did not alter the shock position in the thermochemical non-equilibrium case, opposed to the observed in the perfect gas formulation (see [27]). These values corroborate the observed behavior shown in Fig. 68.

Table 4 presents the values of the aerodynamic drag coefficient in relation to increase values of the $\mathrm{B}_{\mathrm{y}}$ component of the magnetic field. As can be noted, the aerodynamic drag is reduced as the values of the magnetic component are increased. This behavior agrees with that observed in the perfect gas formulation (see [27]).

Finally, Table 5 exhibits the variation of the temperature peak, observed at the configuration nose, with the increased values of the $\mathrm{B}_{\mathrm{y}}$ component of the magnetic field. As can be seen, the temperature at the nose is reduced with the increase of the magnetic field intensity. It is in accord with the perfect gas formulation (see [27]).

\subsection{Quantitative analysis}

In terms of quantitative results, the present author compared the reactive effects coupled with the magnetic effects with the perfect gas solutions. The stagnation pressure at the blunt body nose was evaluated assuming the perfect gas formulation. Such parameter calculated at this way is not the best comparison, but in the absence of practical reactive coupled with magnetic results, this constitutes the best available result.

To calculate the stagnation pressure ahead of the blunt body, [37] presents in its B Appendix values of the normal shock wave properties ahead of the configuration. The ratio $\mathrm{pr}_{0} / \mathrm{pr}_{\infty}$ is estimated as function of the 
normal Mach number and the stagnation pressure $\mathrm{pr}_{0}$ can be determined from this parameter. Hence, to a freestream Mach number of 9.0 (close to 8.78), the ratio $\mathrm{pr}_{0} / \mathrm{pr}_{\infty}$ assumes the value 104.8. The value of $\mathrm{pr}_{\infty}$ is determined by the following expression:

$$
\mathrm{pr}_{\infty}=\frac{\mathrm{pr}_{\text {initial }}}{\rho_{\infty} \times \mathrm{a}_{\infty}^{2}}
$$

In the present study, $\mathrm{pr}_{\text {initial }}=687 \mathrm{~N} / \mathrm{m}^{2}, \rho_{\infty}=0.004 \mathrm{~kg} / \mathrm{m}^{3}$ and $\mathrm{a}_{\infty}=317.024 \mathrm{~m} / \mathrm{s}$. Considering these values, one concludes that $\mathrm{pr}_{\infty}=1.709$ (non-dimensional). Using the ratio obtained from [37], the stagnation pressure ahead of the configuration nose is estimated as 179.10 unities. Table 6 compares the values obtained from the simulations with this theoretical parameter and presents the numerical percentage errors. As can be observed, the best combination was the Maciel scheme employing the [20] artificial dissipation model, in the viscous case, for the [24] chemical model, with an error of $13.31 \%$, which can be considered a good result. This solution was only observed with the Euler Backward time integration method.

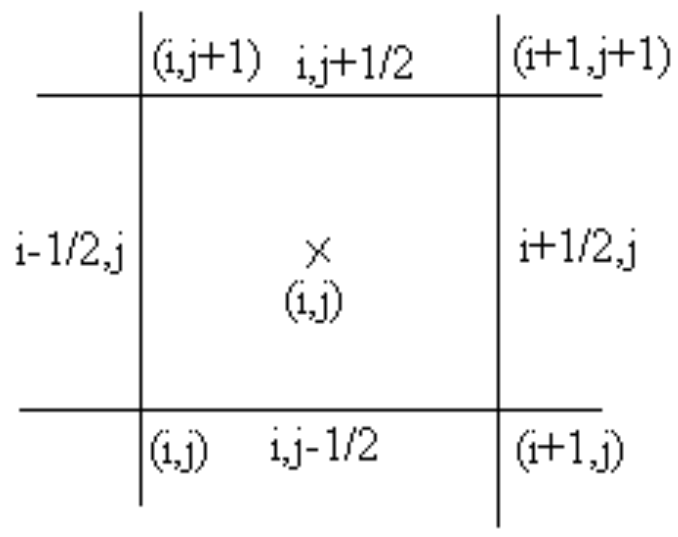

Fig. 1. Computational cell

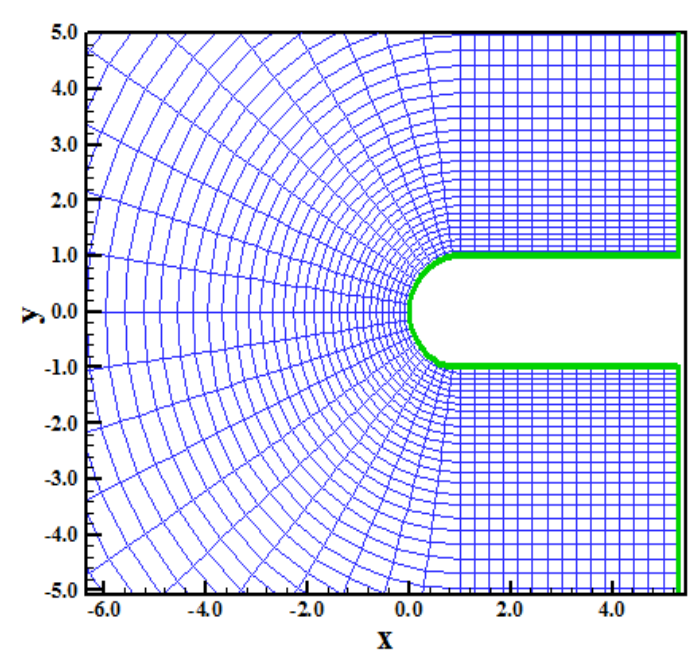

Fig. 3. Blunt body viscous mesh

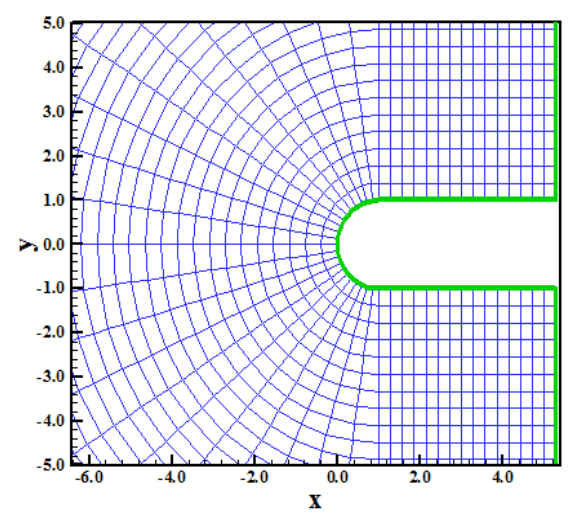

Fig. 2. Blunt body inviscid mesh

INVISCID CASE / Euler Backward

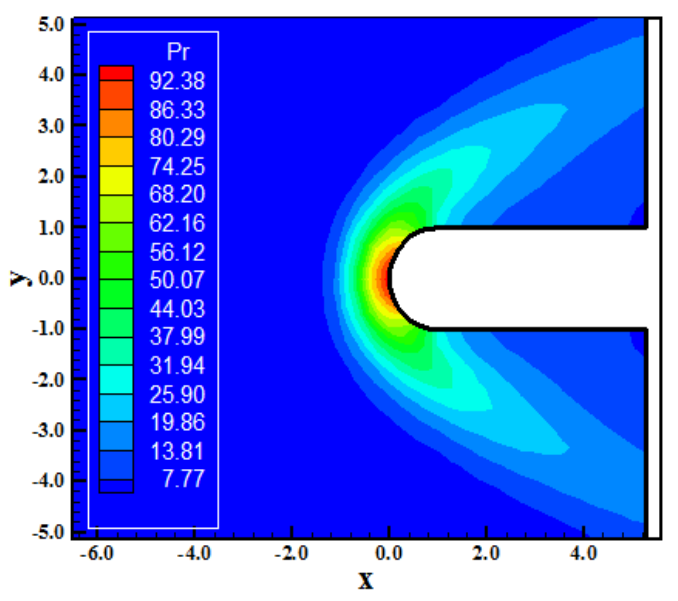

Fig. 4. Pressure contours (DK-MAV) 


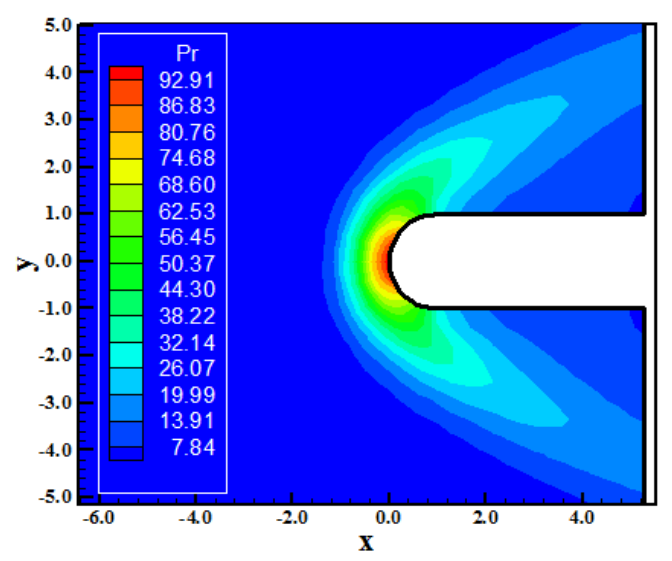

Fig. 5. Pressure contours (Park-MAV)

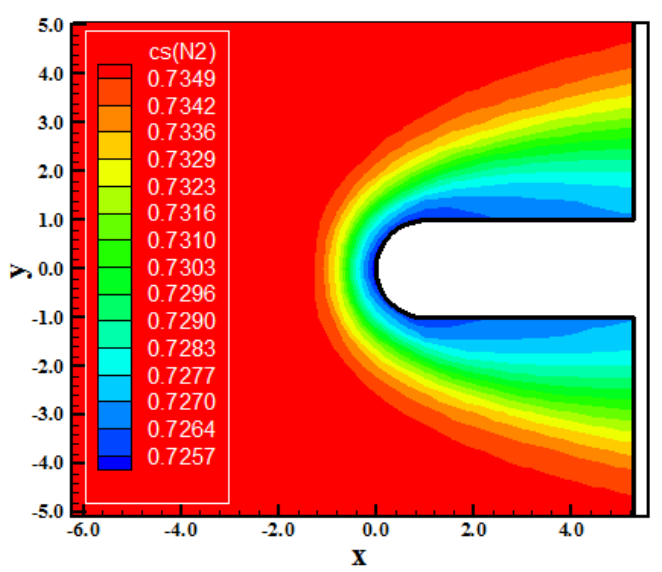

Fig. 7. $\mathrm{N}_{2}$ mass fraction contours (Park-MAV)

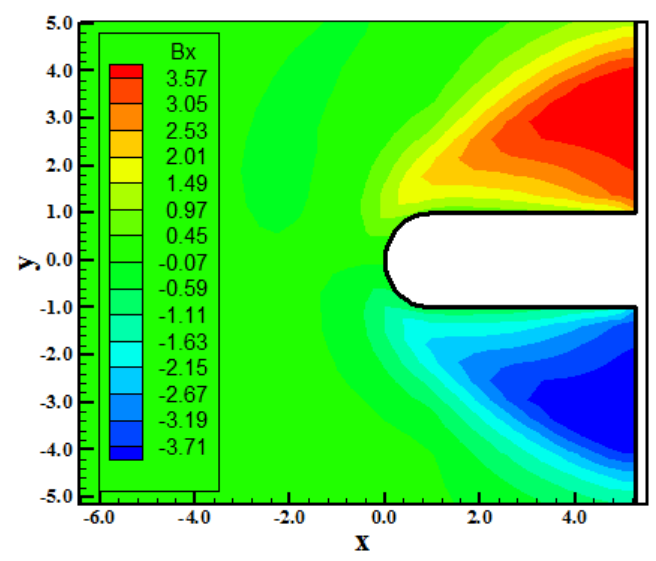

Fig. 9. $B_{x}$ component contours (Park-MAV)

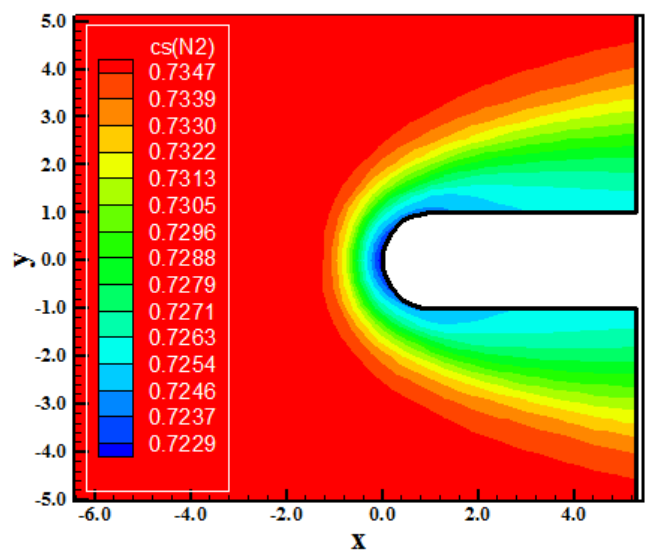

Fig. 6. $\mathrm{N}_{2}$ mass fraction contours (DK-MAV)

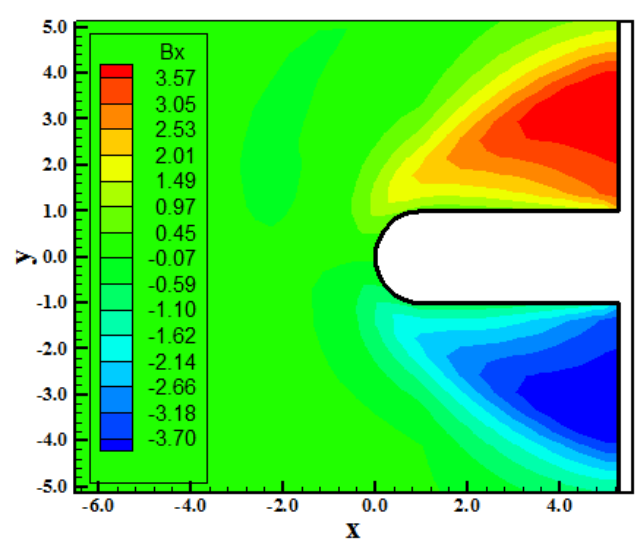

Fig. 8. $B_{x}$ component contours (DK-MAV)

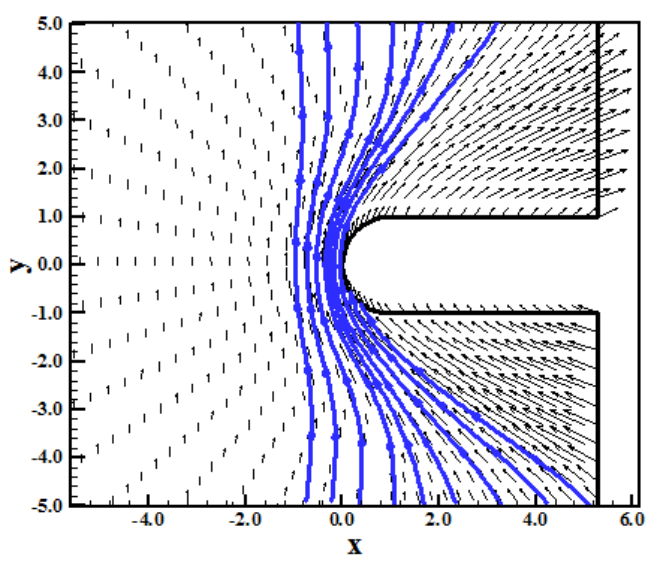

Fig. 10. Induction lines (DK-MAV) 


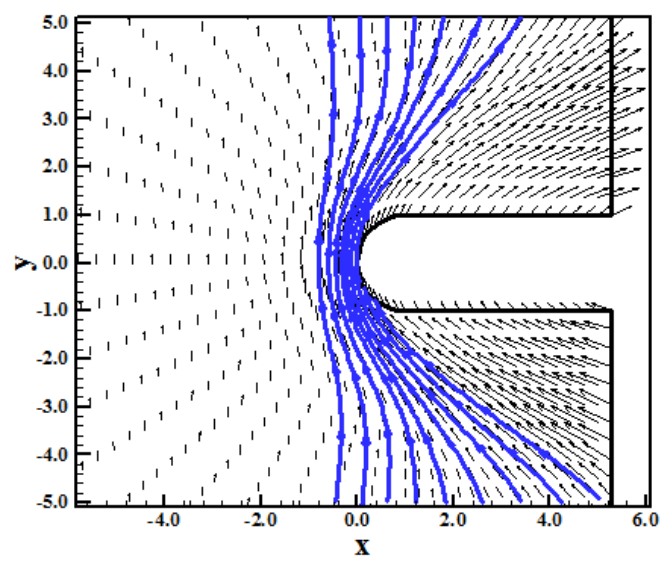

Fig. 11. Induction lines (Park-MAV)

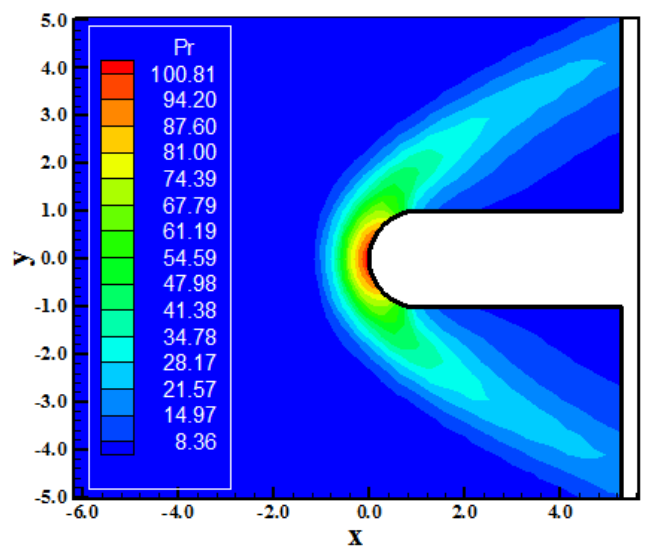

Fig. 13. Pressure contours (Park-TV)

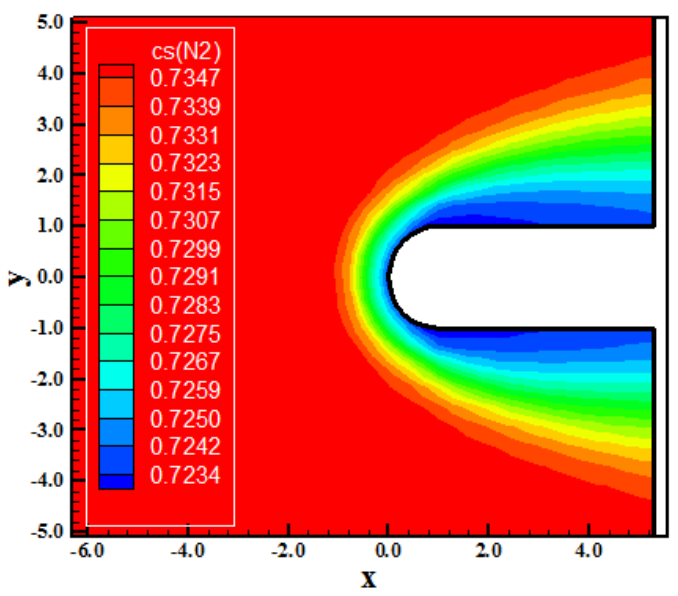

Fig. 15. $\mathrm{N}_{2}$ mass fraction contours (Park-TV)

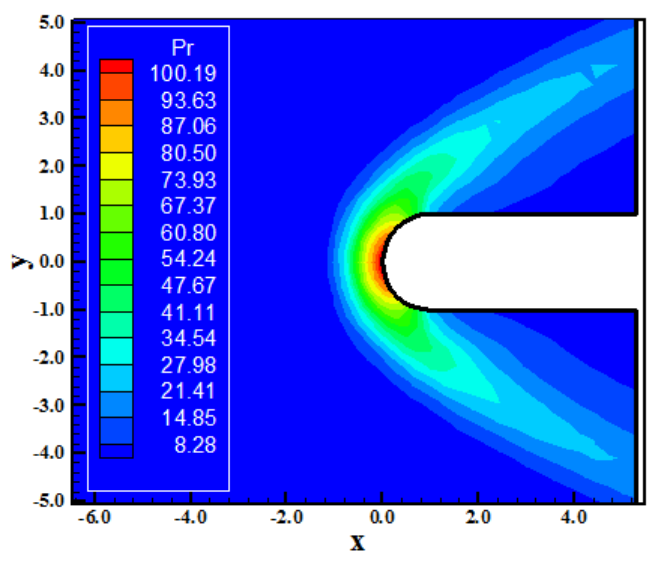

Fig. 12. Pressure contours (DK-TV)

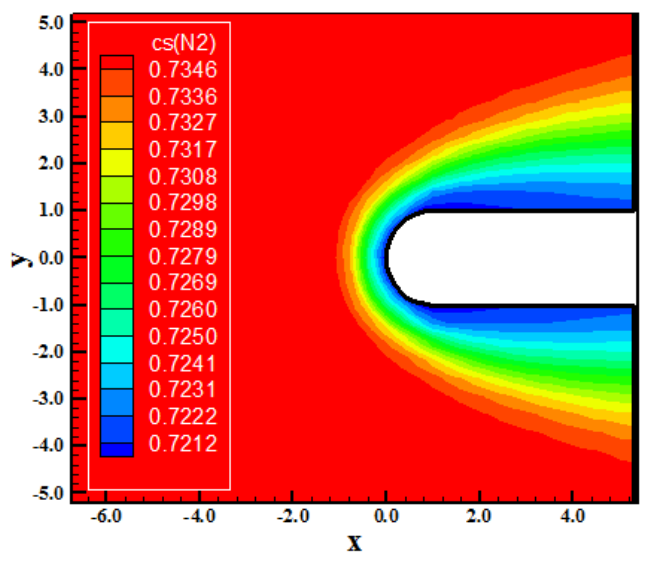

Fig. 14. $\mathrm{N}_{2}$ mass fraction contours (DK-TV)

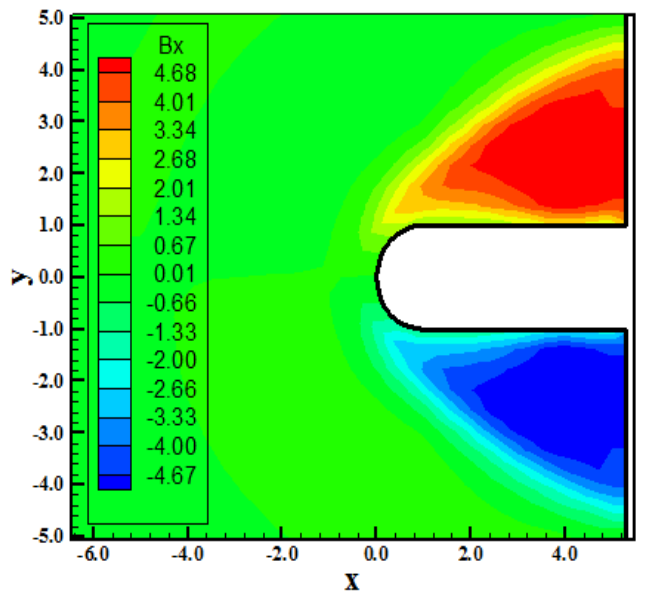

Fig. 16. $B_{x}$ component contours (DK-TV). 


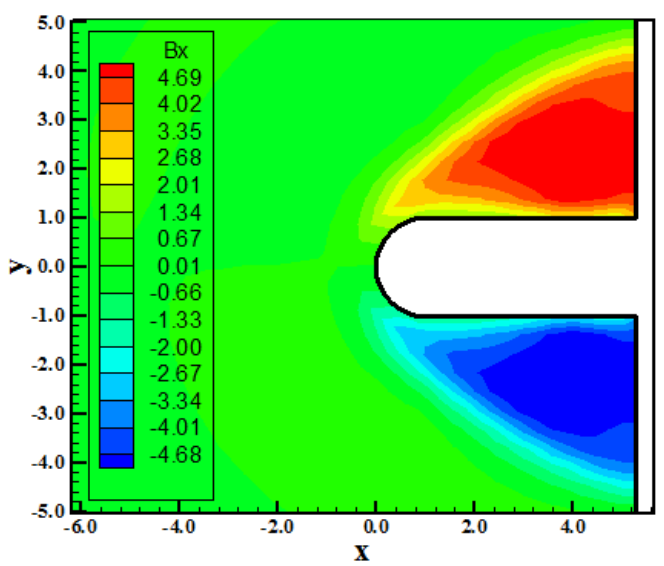

Fig. 17. $B_{x}$ component contours (Park-TV).

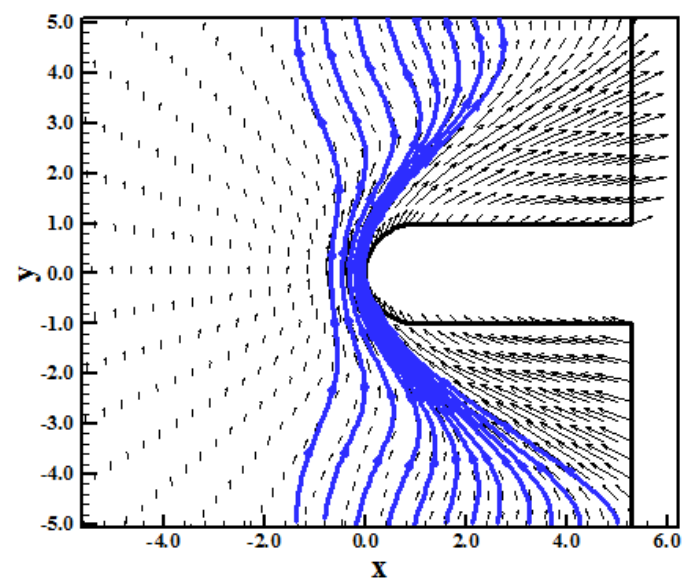

Fig. 19. Induction lines (Park-TV)

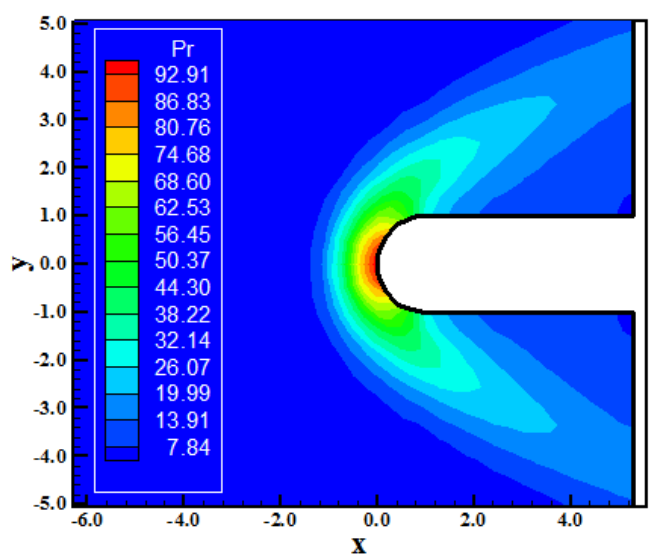

Fig. 21. Pressure contours (Park-MAV)

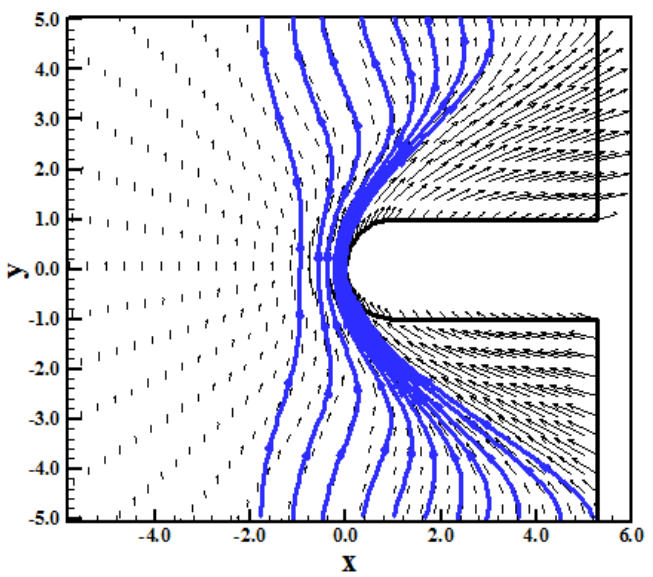

Fig. 18. Induction lines (DK-TV)

INVISCID CASE / Middle Point

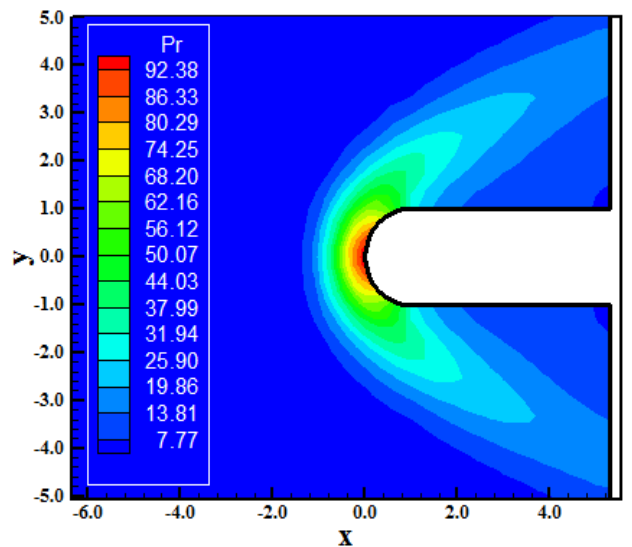

Fig. 20. Pressure contours (DK-MAV)

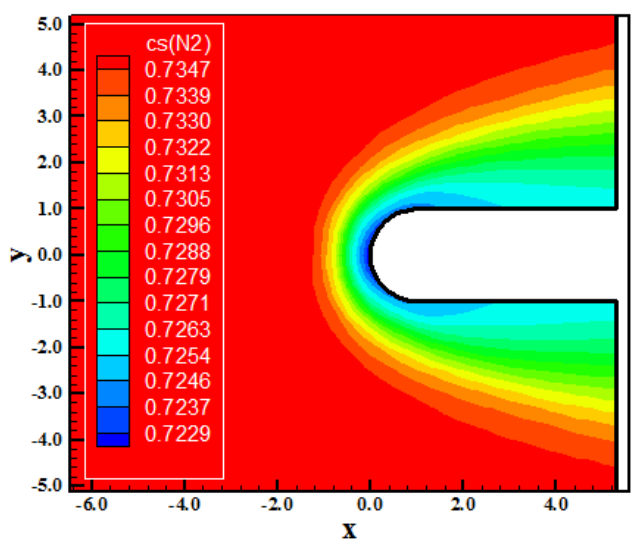

Fig. 22. $\mathrm{N}_{2}$ mass fraction contours (DK-MAV) 


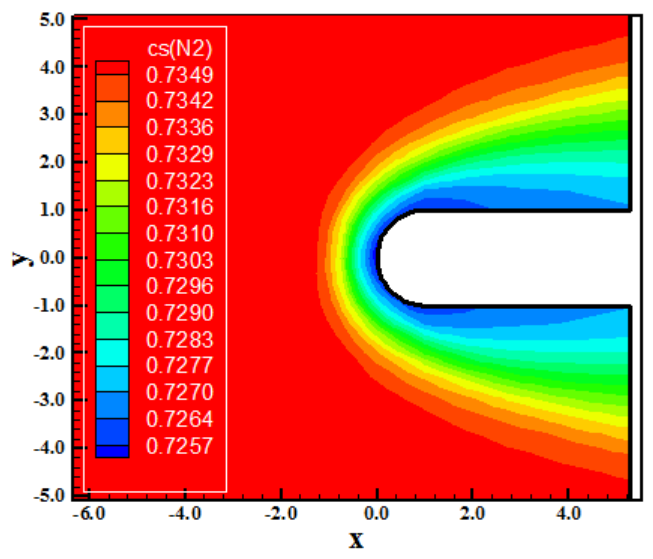

Fig. 23. $\mathrm{N}_{2}$ mass fraction contours (Park-MAV)

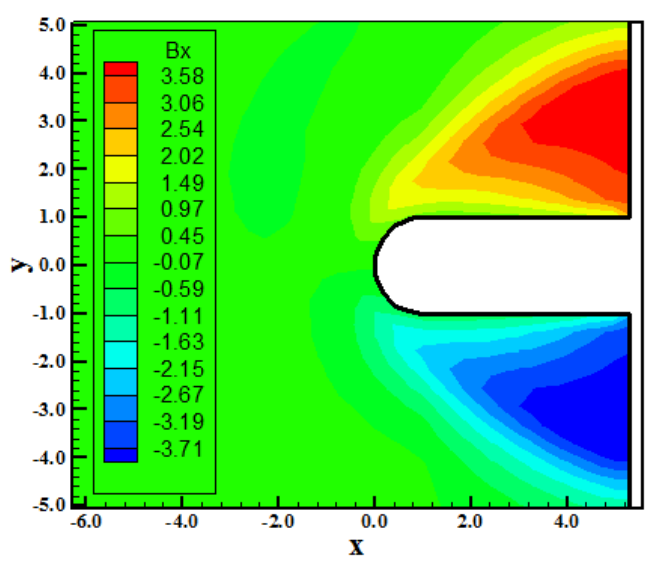

Fig. 25. $B_{x}$ component contours (Park-MAV)

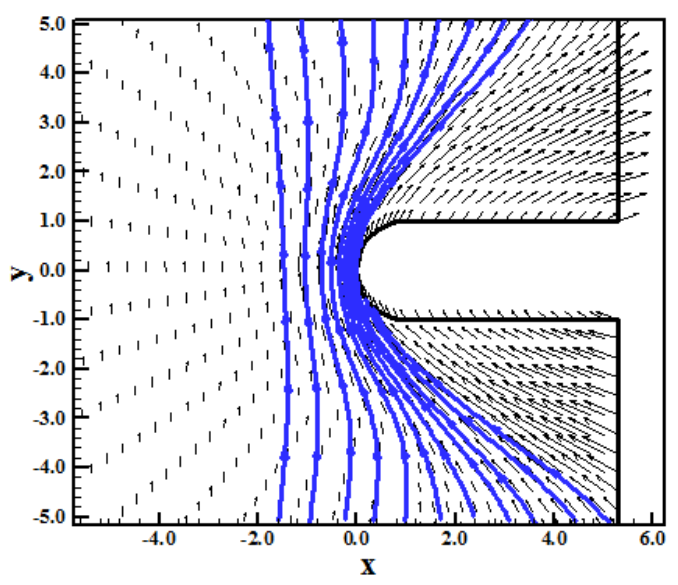

Fig. 27. Induction lines (Park-MAV)

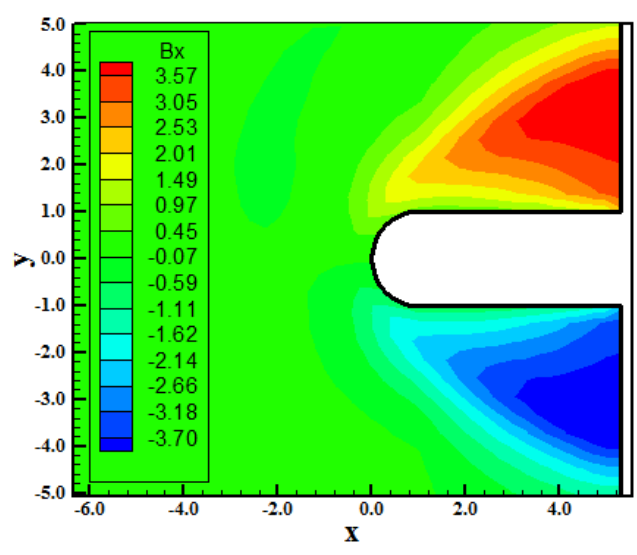

Fig. 24. $B_{x}$ component contours (DK-MAV).

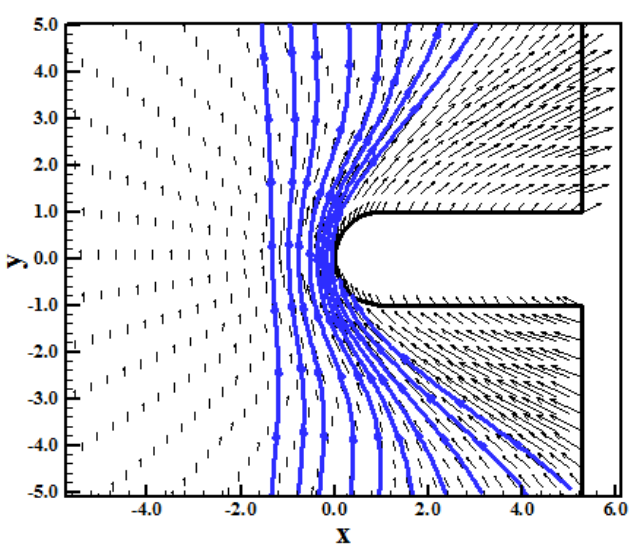

Fig. 26. Induction lines (DK-MAV)

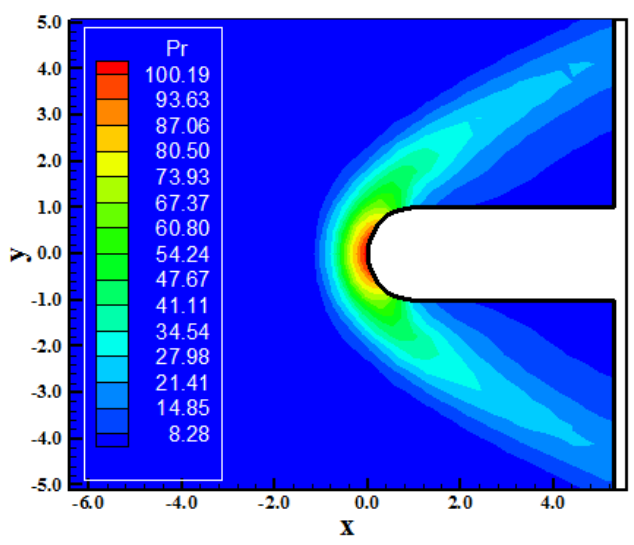

Fig. 28. Pressure contours (DK-TV) 


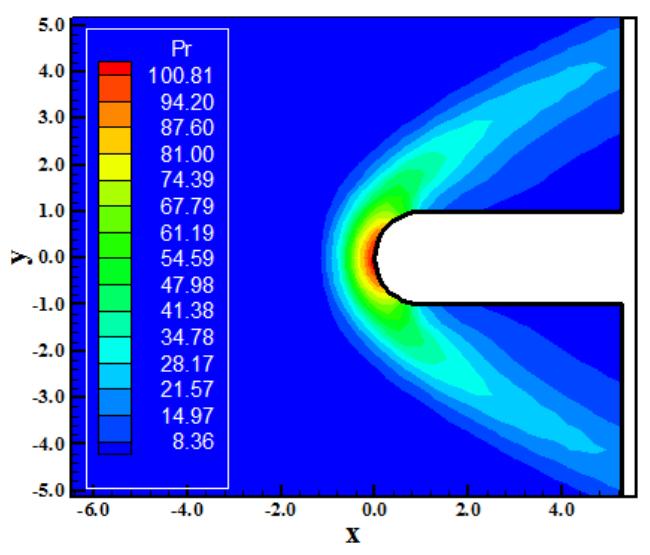

Fig. 29. Pressure contours (Park-TV)

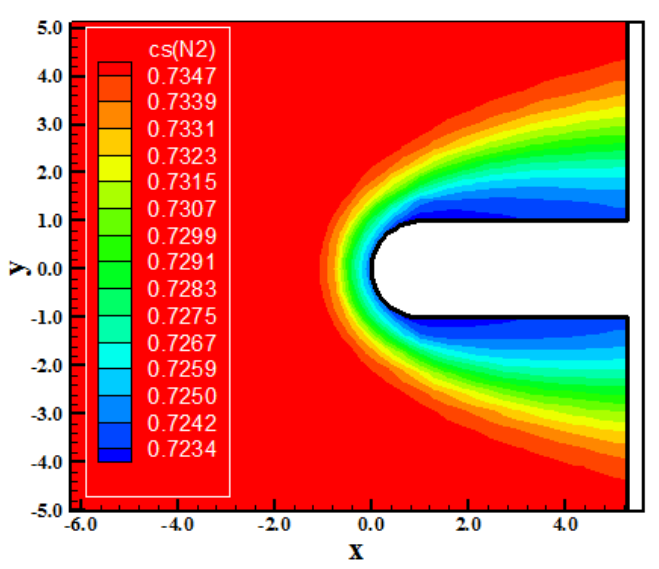

Fig. 31. $\mathrm{N}_{2}$ mass fraction contours (Park-TV)

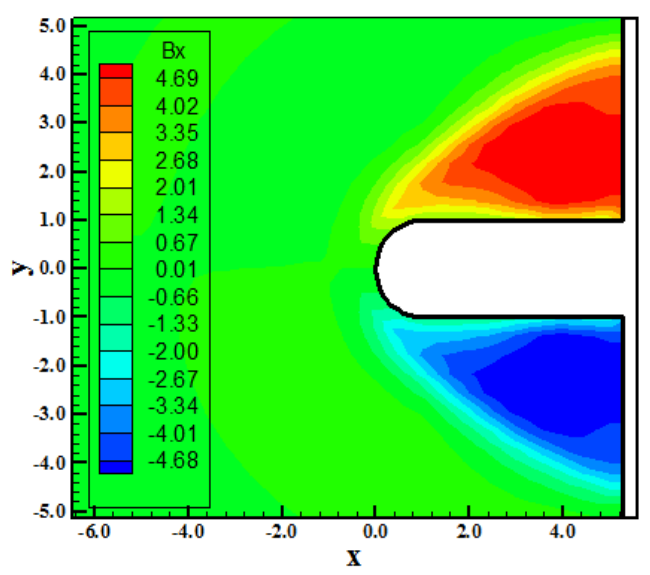

Fig. 33. $B_{x}$ component contours (Park-TV)

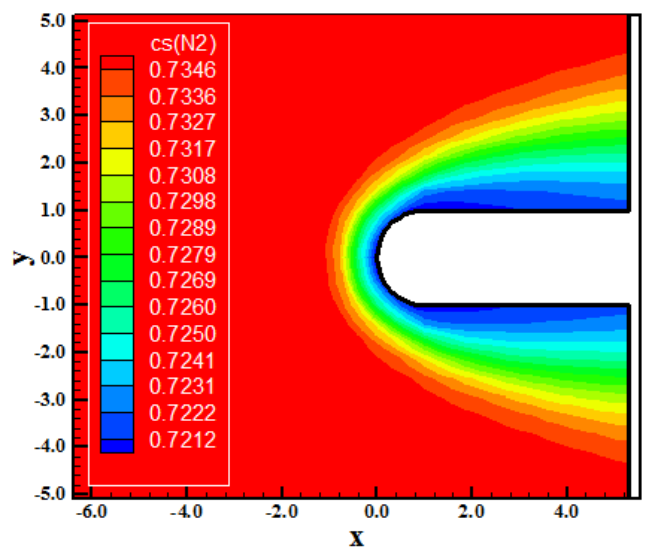

Fig. 30. $\mathrm{N}_{2}$ mass fraction contours (DK-TV)

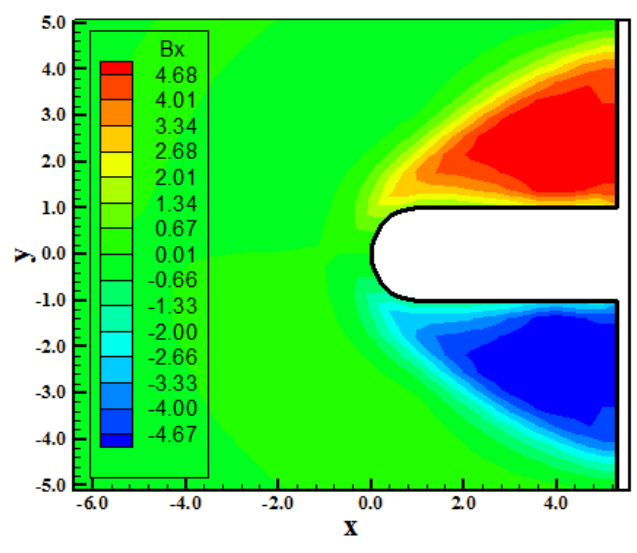

Fig. 32. $B_{x}$ component contours (DK-TV)

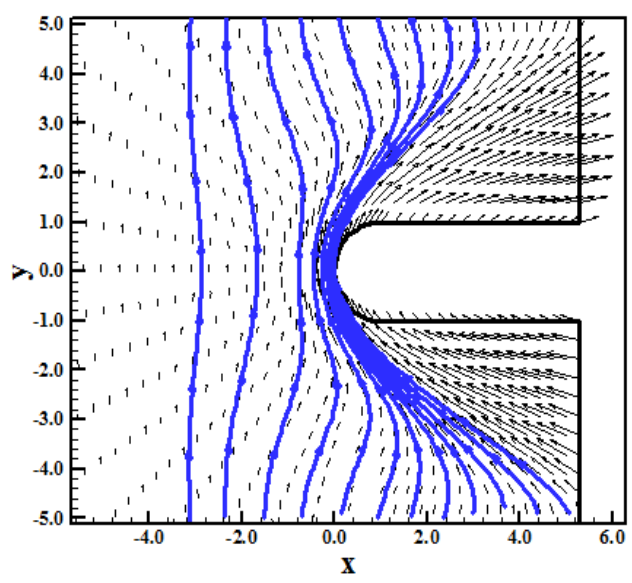

Fig. 34. Induction lines (DK-TV) 


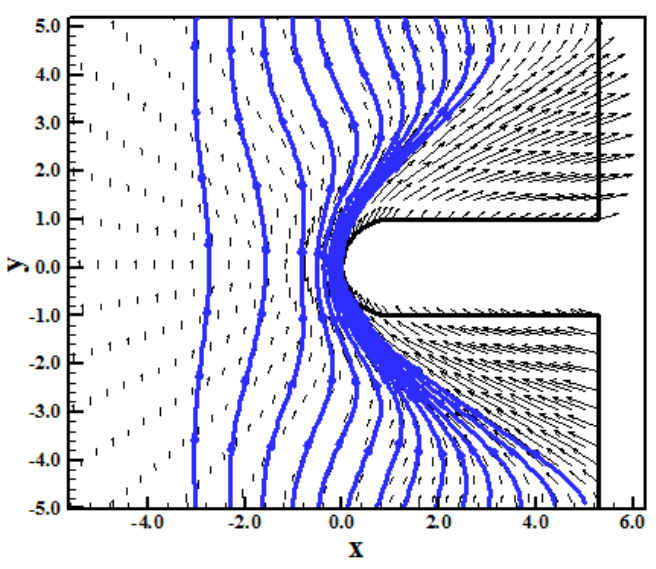

Fig. 35. Induction lines (Park-TV)

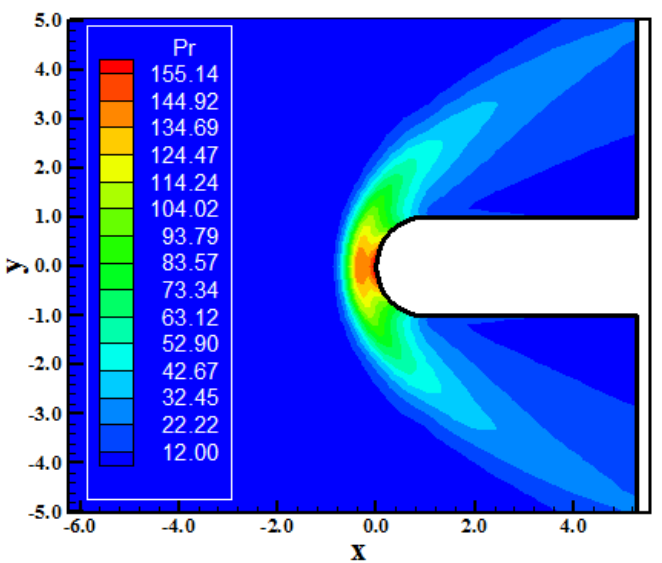

Fig. 37. Pressure contours (Park-MAV)

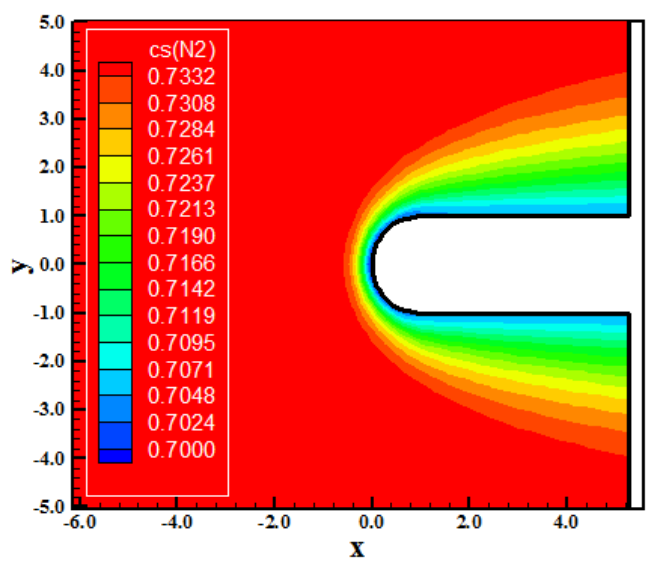

Fig. 39. $\mathrm{N}_{2}$ mass fraction contours (Park-MAV)
VISCOUS CASE / Euler Backward

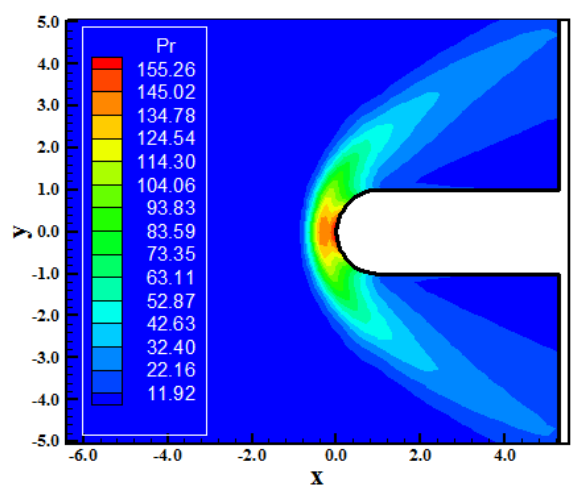

Fig. 36. Pressure contours (DK-MAV)

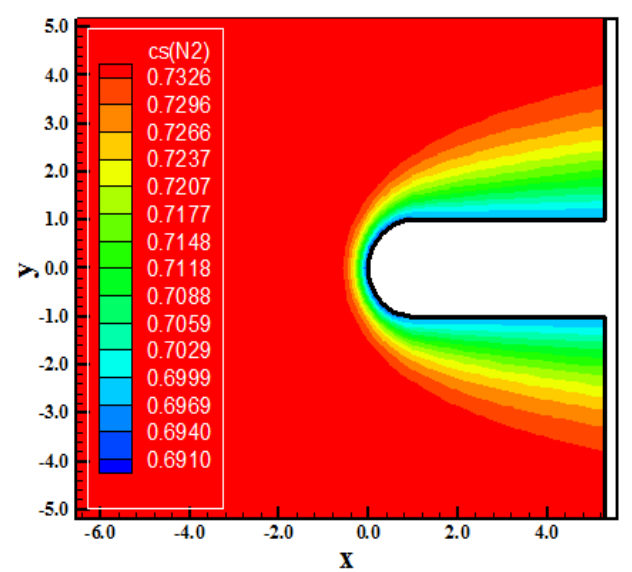

Fig. 38. $\mathrm{N}_{2}$ mass fraction contours (DK-MAV)

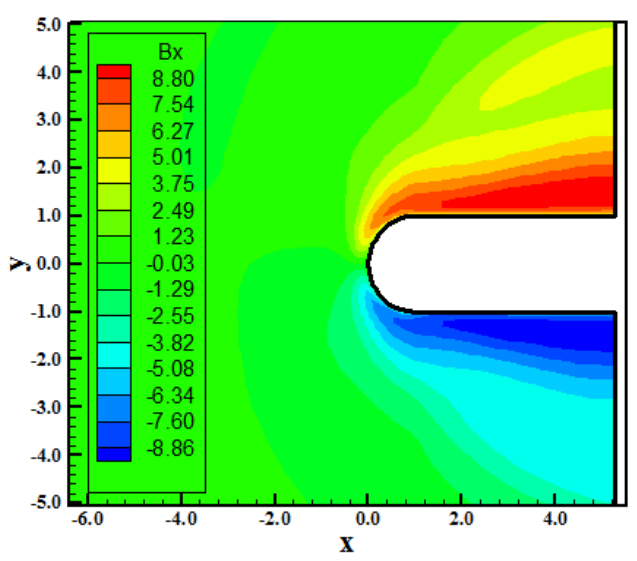

Fig. 40. $B_{x}$ component contours (DK-MAV) 


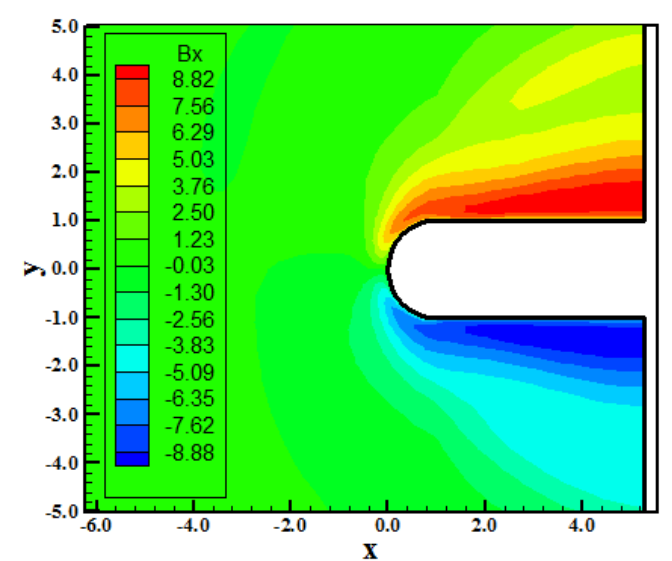

Fig. 41. $B_{x}$ component contours (Park-MAV)

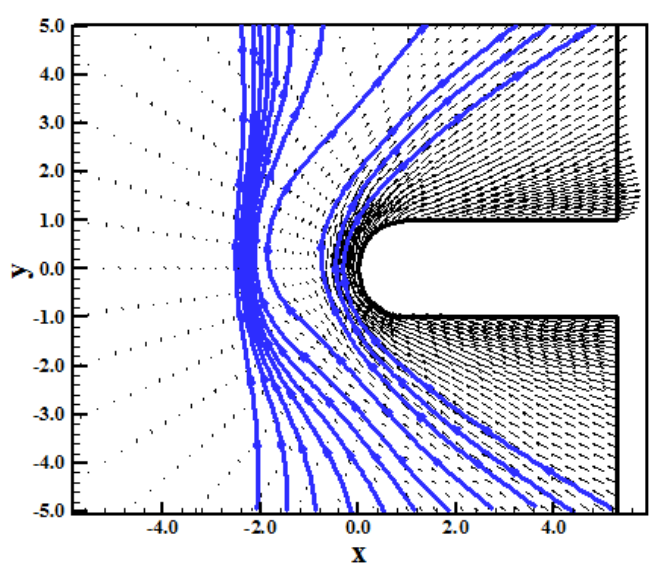

Fig. 43. Induction lines (Park-MAV)

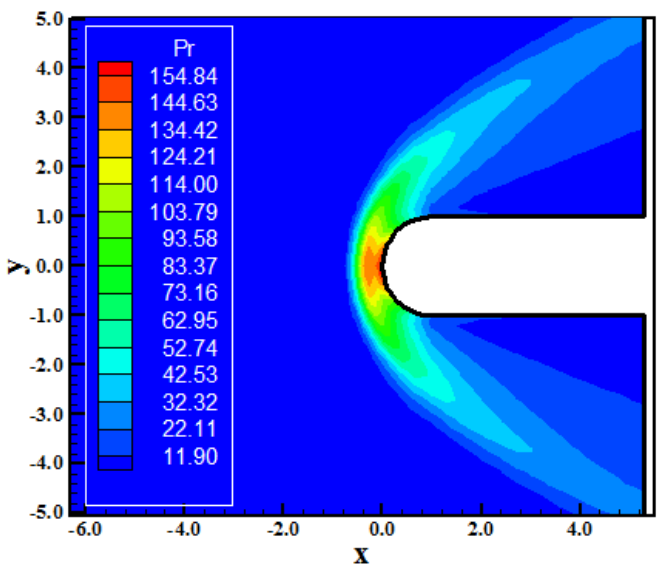

Fig. 45. Pressure contours (Park-TV)

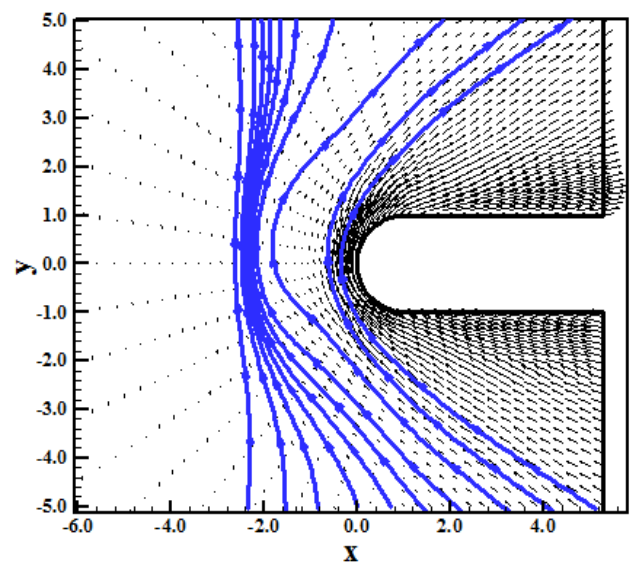

Fig. 42. Induction lines (DK-MAV)

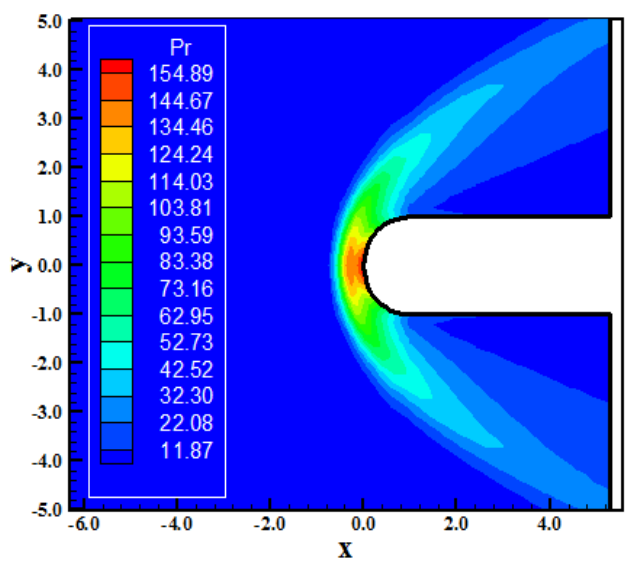

Fig. 44. Pressure contours (DK-TV)

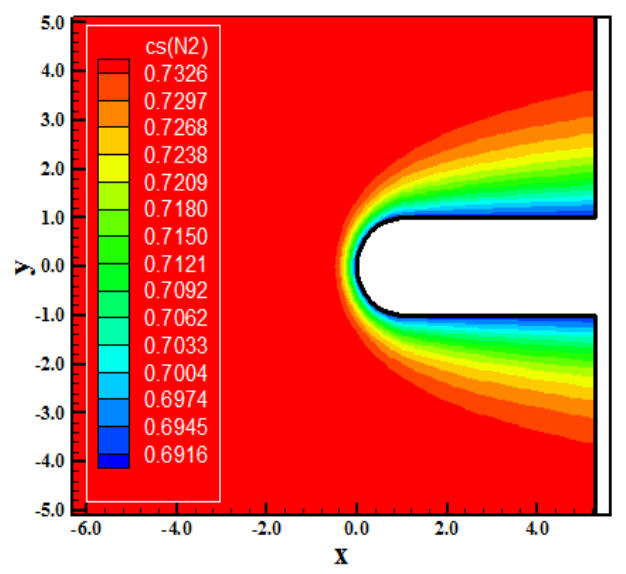

Fig. 46. $\mathrm{N}_{2}$ mass fraction contours (DK-TV) 


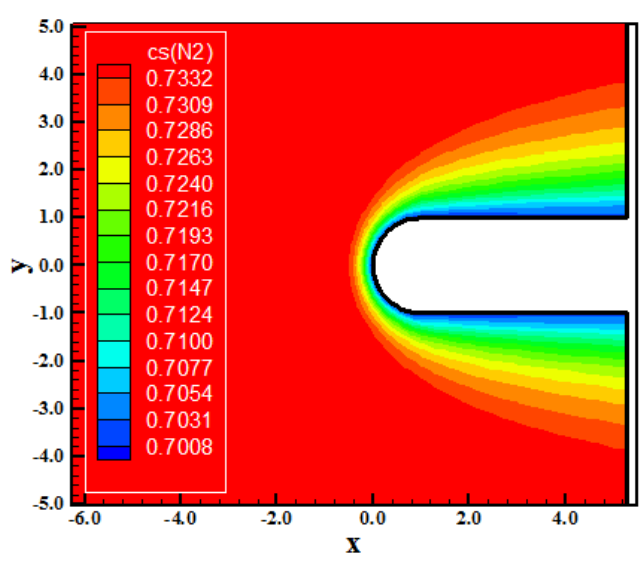

Fig. 47. $\mathrm{N}_{2}$ mass fraction contours (Park-TV)

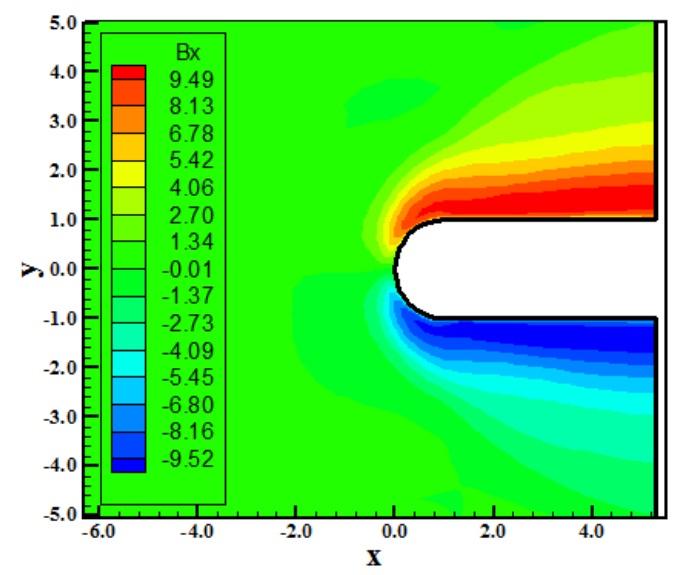

Fig. 49. $B_{x}$ component contours (Park-TV)

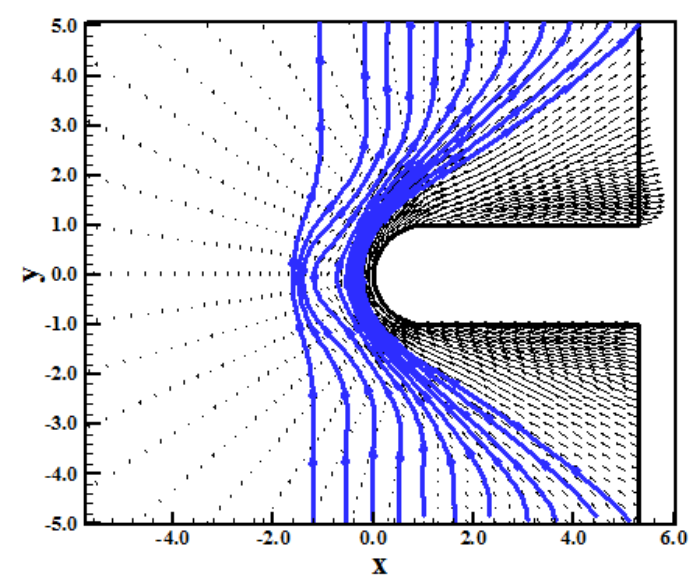

Fig. 51. Induction lines (Park-TV)

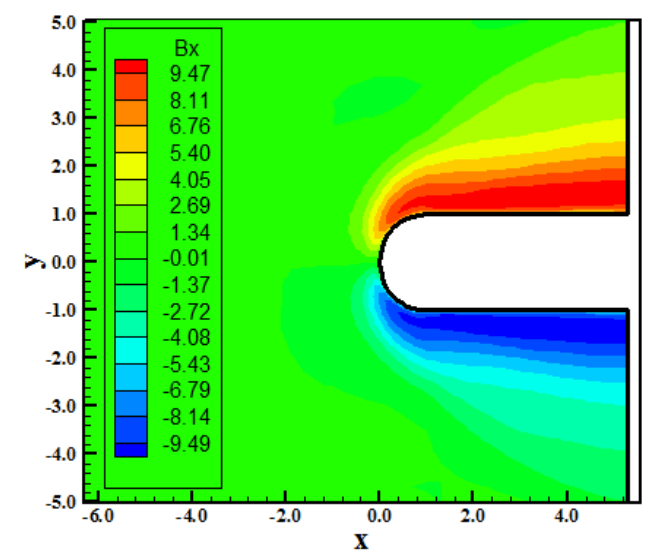

Fig. 48. $B_{x}$ component contours (DK-TV)

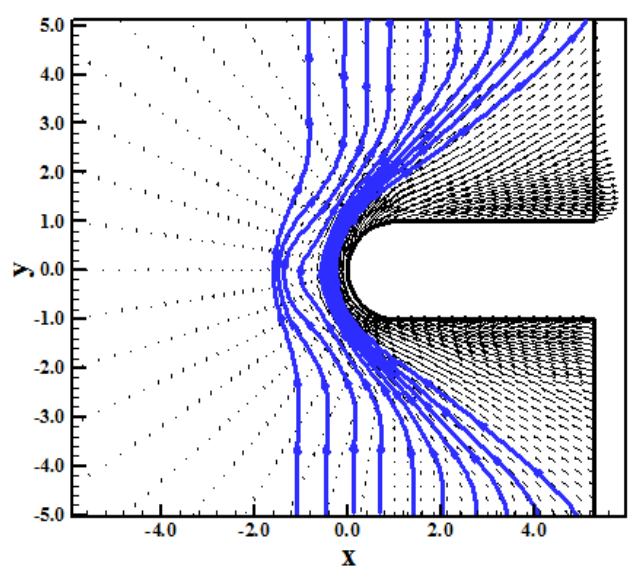

Fig. 50. Induction lines (DK-TV)

VISCOUS CASE / Middle Point

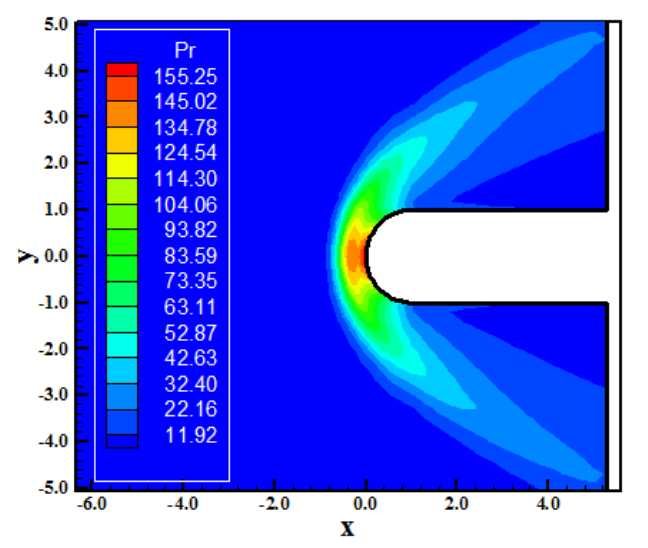

Fig. 52. Pressure contours (DK-MAV) 


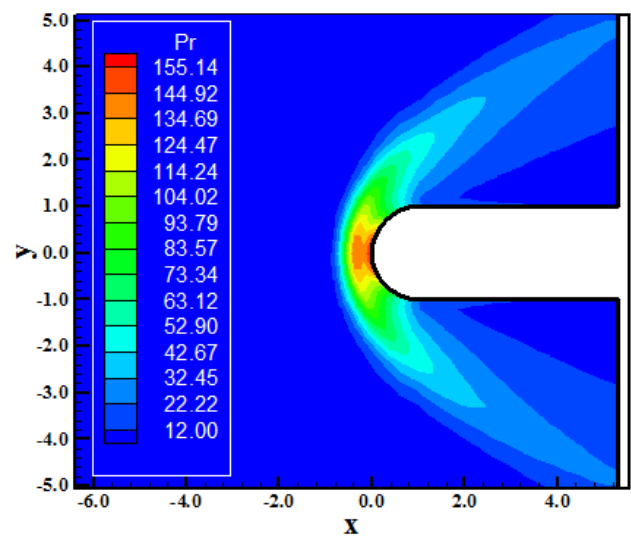

Fig. 53. Pressure contours (Park-MAV)

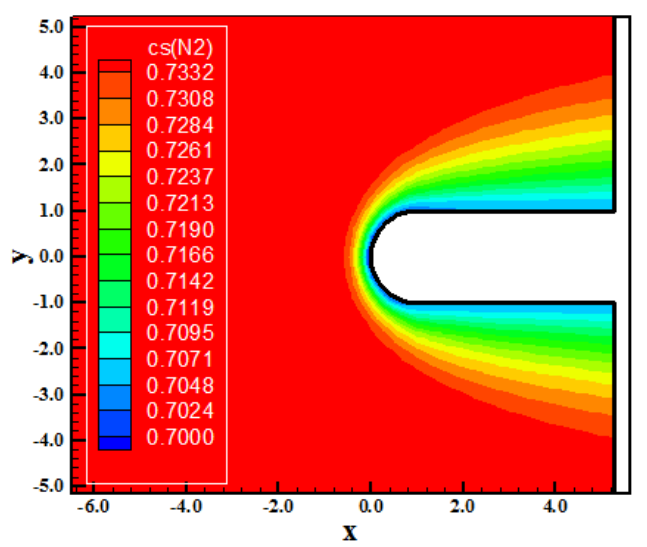

Fig. 55. $\mathrm{N}_{2}$ mass fraction contours (Park-MAV)

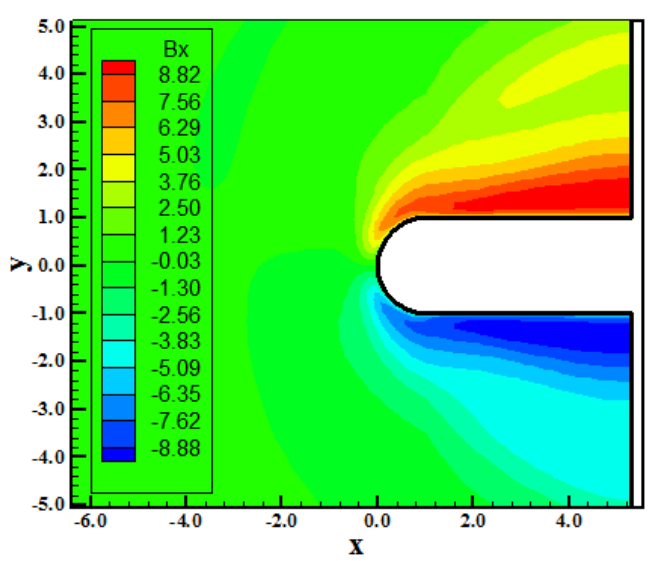

Fig. 57. $B_{x}$ component contours (Park-MAV)

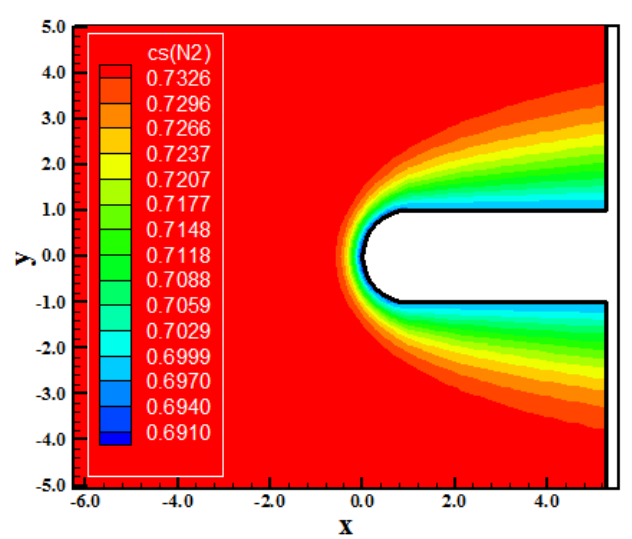

Fig. 54. $N_{2}$ mass fraction contours (DK-MAV)

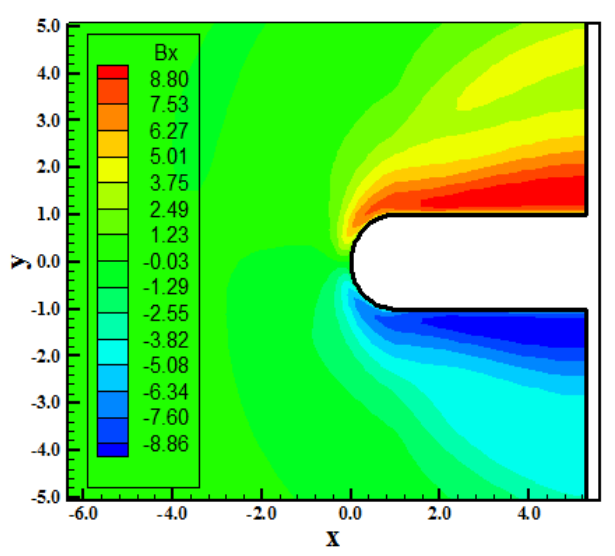

Fig. 56. $B_{x}$ component contours (DK-MAV)

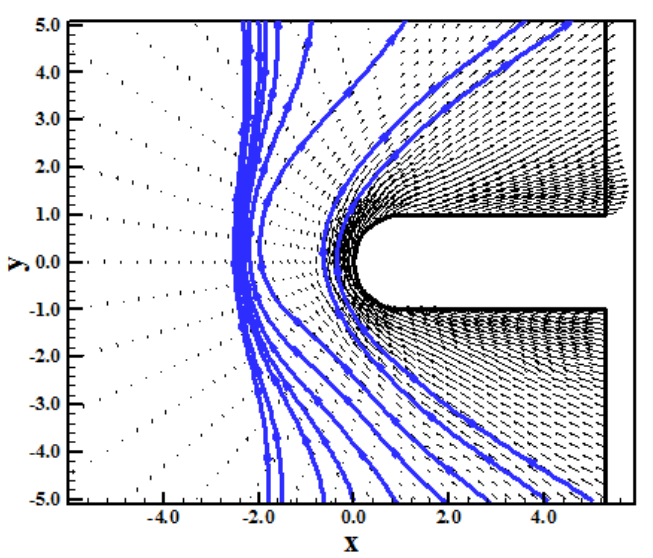

Fig. 58. Induction lines (DK-MAV) 


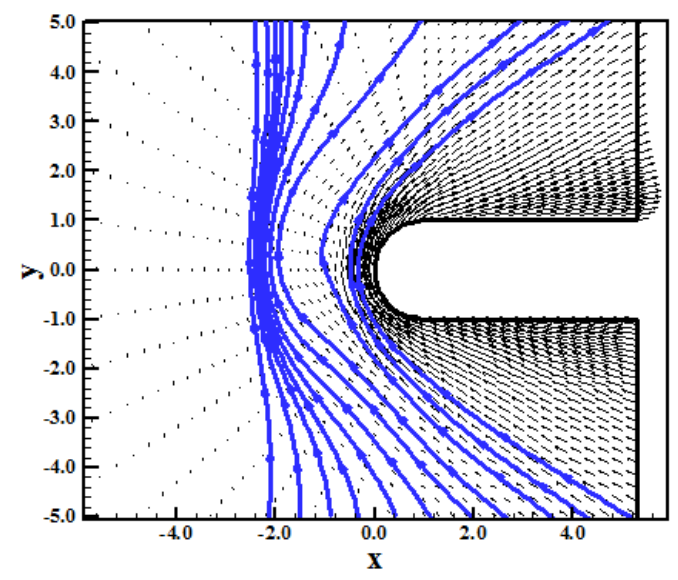

Fig. 59. Induction lines (Park-MAV)

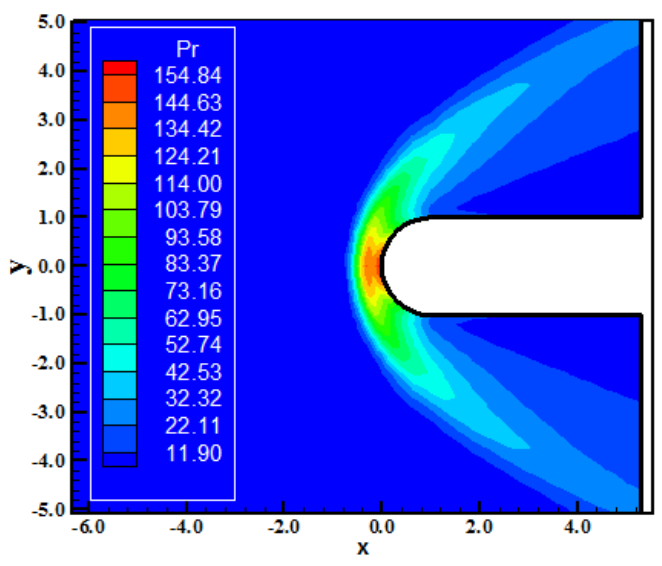

Fig. 61. Pressure contours (Park-TV)

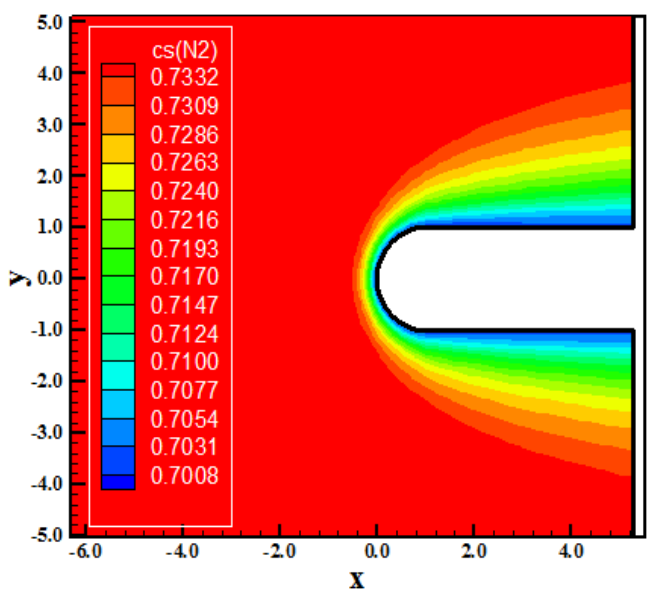

Fig. 63. $\mathrm{N}_{2}$ mass fraction contours (Park-TV)

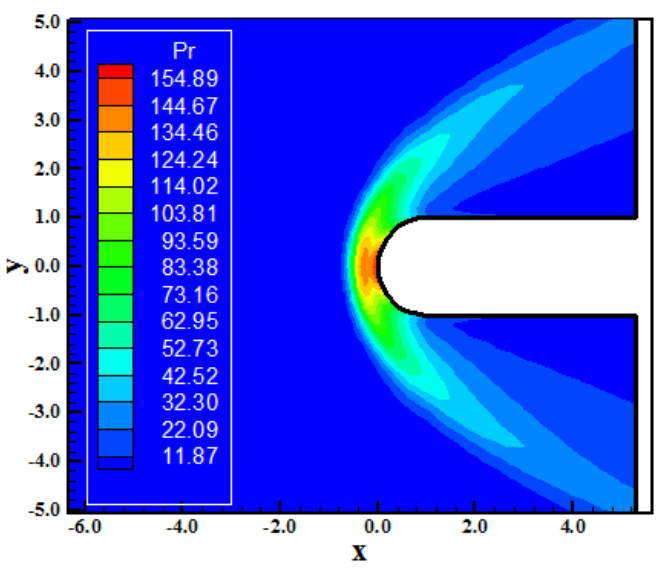

Fig. 60. Pressure contours (DK-TV)

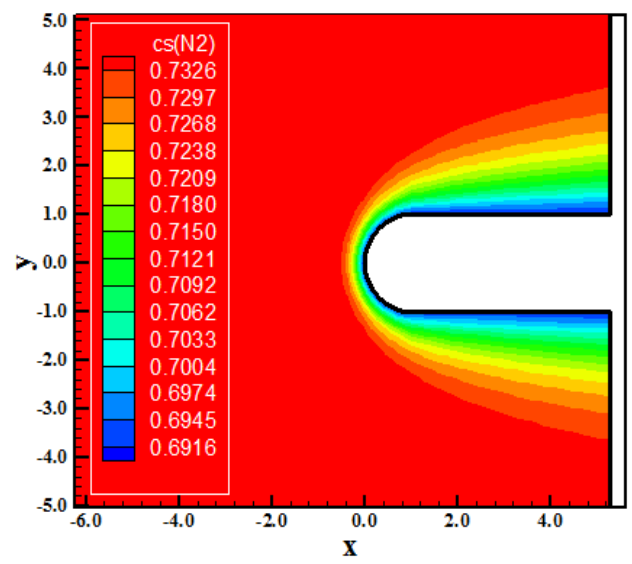

Fig. 62. $\mathrm{N}_{2}$ mass fraction contours (DK-TV)

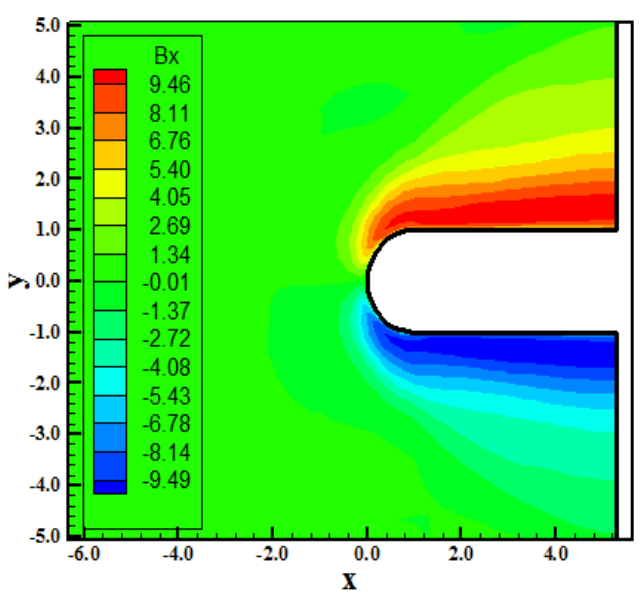

Fig. 64. $B_{x}$ component contours (DK-TV) 


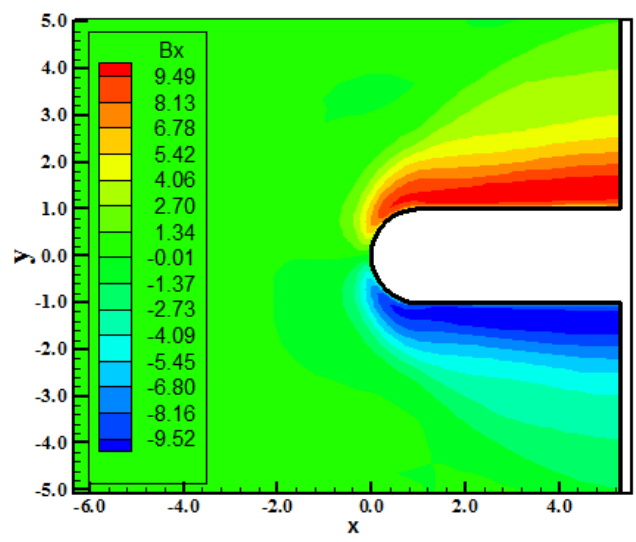

Fig. 65. $B_{x}$ component contours (Park-TV)

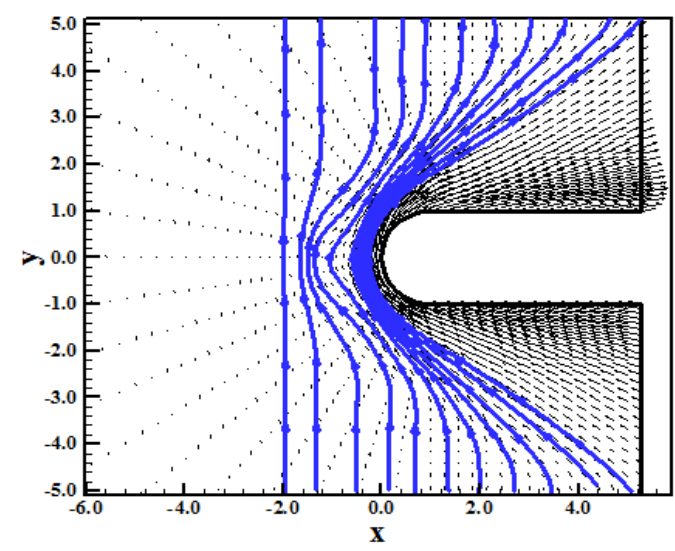

Fig. 67. Induction lines (Park-TV)

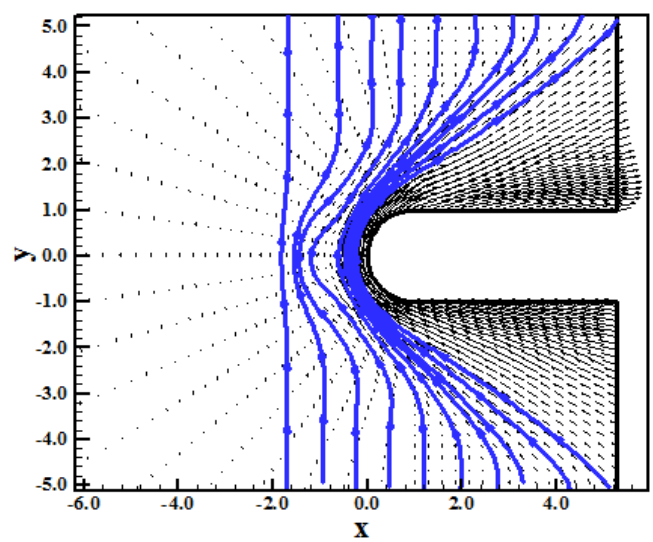

Fig. 66. Induction lines (DK-TV)

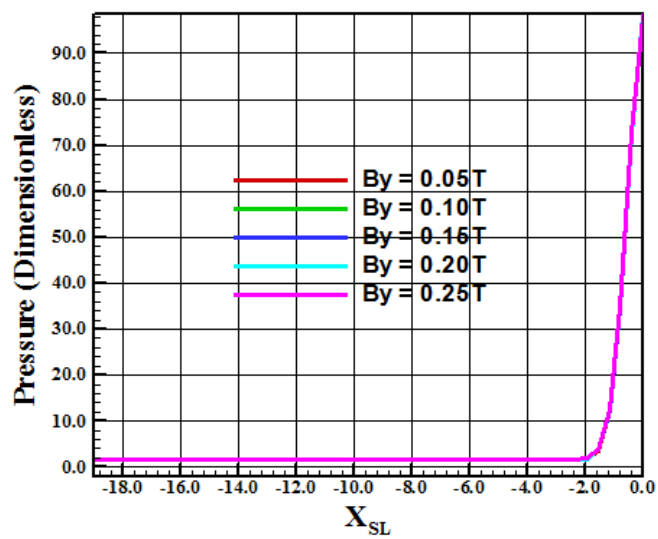

Fig. 68. Pressure distribution at the stagnation line

Table 1. Values of $S_{x}$ and $S_{y}$

\begin{tabular}{lll}
\hline Surface & $\mathbf{S}_{\mathbf{x}}$ & $\mathbf{S}_{\mathbf{y}}$ \\
\hline $\mathrm{i}, \mathrm{j}-1 / 2$ & $\left(\mathrm{y}_{\mathrm{i}+1, \mathrm{j}}-\mathrm{y}_{\mathrm{i}, \mathrm{j}}\right)$ & $\left(\mathrm{x}_{\mathrm{i}, \mathrm{j}}-\mathrm{x}_{\mathrm{i}+1, \mathrm{j}}\right)$ \\
$\mathrm{i}+1 / 2, \mathrm{j}$ & $\left(\mathrm{y}_{\mathrm{i}+1, \mathrm{j}+1}-\mathrm{y}_{\mathrm{i}+1, \mathrm{j}}\right)$ & $\left(\mathrm{x}_{\mathrm{i}+1, \mathrm{j}}-\mathrm{x}_{\mathrm{i}+1, \mathrm{j}+1}\right)$ \\
$\mathrm{i}, \mathrm{j}+1 / 2$ & $\left(\mathrm{y}_{\mathrm{i}, \mathrm{j}+1}-\mathrm{y}_{\mathrm{i}+1, \mathrm{j}+1}\right)$ & $\left(\mathrm{x}_{\mathrm{i}+1, \mathrm{j}+1}-\mathrm{x}_{\mathrm{i}, \mathrm{j}+1}\right)$ \\
$\mathrm{i}-1 / 2, \mathrm{j}$ & $\left(\mathrm{y}_{\mathrm{i}, \mathrm{j}}-\mathrm{y}_{\mathrm{i}, \mathrm{j}+1}\right)$ & $\left(\mathrm{x}_{\mathrm{i}, \mathrm{j}+1}-\mathrm{x}_{\mathrm{i}, \mathrm{j}}\right)$ \\
\hline
\end{tabular}

\subsection{Computational performance}

Table 7 presents the computational data of the Maciel scheme for the blunt body problem. It shows the CFL number and the number of iterations to convergence for all studied cases in the present work. As can be seen, the best performance is due to Maciel scheme employing the [24] chemical model, using the [20] artificial dissipation model and the Euler Backward time integration method for the inviscid case. For the viscous case, the best performance is due to the Maciel scheme employing the [24] chemical model, using the [21] artificial dissipation model and the Middle Point time integration method to march in time. 
Table 2. Initial conditions to the problem of the blunt body

\begin{tabular}{ll}
\hline Property & Value \\
\hline $\mathrm{M}_{\infty}$ & 8.78 \\
$\rho_{\infty}$ & $0.00326 \mathrm{~kg} / \mathrm{m}^{3}$ \\
$\mathrm{p}_{\infty}$ & $687 \mathrm{~Pa}$ \\
$\mathrm{U}_{\infty}$ & $4,776 \mathrm{~m} / \mathrm{s}$ \\
$\mathrm{T}_{\infty}$ & $694 \mathrm{~K}$ \\
$\mathrm{~T}_{\mathrm{v}, \infty}$ & $694 \mathrm{~K}$ \\
$\mathrm{~T}_{\mathrm{REF}}$ & $0 \mathrm{~K}$ \\
Altitude & $40,000 \mathrm{~m}$ \\
$\mathrm{c}_{\mathrm{N}}$ & $10^{-9}$ \\
$\mathrm{c}_{\mathrm{O}}$ & 0.07955 \\
$\mathrm{c}_{\mathrm{O}_{2}}$ & 0.13400 \\
$\mathrm{c}_{\mathrm{NO}}$ & 0.05090 \\
$\mathrm{c}_{\mathrm{N}^{+}}$ & 0.0 \\
$\mathrm{c}_{\mathrm{O}^{+}}$ & 0.0 \\
$\mathrm{c}_{\mathrm{N}_{2}^{+}}$ & 0.0 \\
$\mathrm{c}_{\mathrm{O}_{2}^{+}}$ & \\
$\mathrm{c}_{\mathrm{NO}}$ & 0.0 \\
$\mathrm{c}_{\mathrm{e}-}$ & 0.0 \\
$\mathrm{~L}_{\mathrm{REF}}$ & 0.0 \\
$\mathrm{Re}_{\infty}$ & $2.0 \mathrm{~m}$ \\
$\mathrm{~B}_{\mathrm{y}, \infty}$ & $2.3885 \times 10^{6}$ \\
$\mu_{\mathrm{M}, \infty}$ & $0.15 \mathrm{~T}$ \\
$\sigma_{\infty}$ & $1.2566 \times 10^{-6} \mathrm{~T} . \mathrm{m} / \mathrm{A}$ \\
\hline
\end{tabular}

Table 3. Shock-standoff distance

\begin{tabular}{ll}
\hline $\mathbf{B}_{\mathbf{y}}(\mathbf{T})$ & $\mathbf{X}_{\text {shock }}(\mathbf{m})$ \\
\hline 0.05 & 2.327 \\
0.10 & 2.327 \\
0.15 & 2.327 \\
0.20 & 2.327 \\
0.25 & 2.327 \\
\hline
\end{tabular}

Table 4. Drag aerodynamic coefficient

\begin{tabular}{ll}
\hline $\mathbf{B}_{\mathbf{v}}(\mathbf{T})$ & $\mathbf{c}_{\mathbf{D}}$ \\
\hline 0.05 & 0.931 \\
0.10 & 0.930 \\
0.15 & 0.929 \\
0.20 & 0.927 \\
0.25 & 0.925 \\
\hline
\end{tabular}

As final conclusion, it is possible to highlight the [20] artificial dissipation model as the best in the estimative of the stagnation pressure ahead of the blunt body. The Maciel scheme employing the [24] chemical model, using the [20] artificial dissipation model in the inviscid case and with the Euler Backward method was the most efficient in terms of computational performance. It is also important to note that both time integration methods studied in this work have obtained the same steady state solutions in each case 
(inviscid and viscous), which allows the conclusion that everyone of such march methods can be used to reach convergence.

Table 5. Temperature at the blunt body nose

\begin{tabular}{ll}
\hline $\mathbf{B}_{\mathbf{y}} \mathbf{( T )}$ & $\mathbf{T} \mathbf{( K )}$ \\
\hline 0.05 & $11,850.80$ \\
0.10 & $11,840.75$ \\
0.15 & $11,823.44$ \\
0.20 & $11,799.76$ \\
0.25 & $11,771.31$ \\
\hline
\end{tabular}

Table 6. Values of stagnation pressure and errors

\begin{tabular}{|c|c|c|c|c|}
\hline March method & Flow Regime & Chemical model & $\mathbf{p r}_{\mathbf{0}}$ & Error (\%) \\
\hline \multirow{4}{*}{$\begin{array}{l}\text { Euler Backward } \\
\text { and [20] model }\end{array}$} & Inviscid & Dunn and Kang & 92.38 & 48.42 \\
\hline & Inviscid & Park & 92.91 & 48.12 \\
\hline & Viscous & Dunn and Kang & 155.26 & 13.31 \\
\hline & Viscous & Park & 155.14 & 13.38 \\
\hline \multirow{4}{*}{$\begin{array}{l}\text { Euler Backward } \\
\text { and [21] model }\end{array}$} & Inviscid & Dunn and Kang & 100.19 & 44.06 \\
\hline & Inviscid & Park & 100.81 & 43.71 \\
\hline & Viscous & Dunn and Kang & 154.89 & 13.52 \\
\hline & Viscous & Park & 154.84 & 13.55 \\
\hline \multirow{4}{*}{$\begin{array}{l}\text { Middle Point } \\
\text { and [20] model }\end{array}$} & Inviscid & Dunn and Kang & 92.38 & 48.42 \\
\hline & Inviscid & Park & 92.91 & 48.12 \\
\hline & Viscous & Dunn and Kang & 155.25 & 13.32 \\
\hline & Viscous & Park & 155.14 & 13.38 \\
\hline \multirow{4}{*}{$\begin{array}{l}\text { Middle Point } \\
\text { and [21] model }\end{array}$} & Inviscid & Dunn and Kang & 100.19 & 44.06 \\
\hline & Inviscid & Park & 100.81 & 43.71 \\
\hline & Viscous & Dunn and Kang & 154.89 & 13.52 \\
\hline & Viscous & Park & 154.84 & 13.55 \\
\hline \multicolumn{5}{|c|}{ Table 7. Computational data } \\
\hline March method & Flow Regime & Chemical model & CFL & Iterations \\
\hline \multirow{4}{*}{$\begin{array}{l}\text { Euler Backward } \\
\text { and [20] model }\end{array}$} & Inviscid & Dunn and Kang & 0.05 & 10,546 \\
\hline & Inviscid & Park & 0.05 & 10,629 \\
\hline & Viscous & Dunn and Kang & 0.05 & 17,320 \\
\hline & Viscous & Park & 0.05 & 16,373 \\
\hline \multirow{4}{*}{$\begin{array}{l}\text { Euler Backward } \\
\text { and [21] model }\end{array}$} & Inviscid & Dunn and Kang & 0.05 & 18,245 \\
\hline & Inviscid & Park & 0.05 & 17,841 \\
\hline & Viscous & Dunn and Kang & 0.05 & 12,899 \\
\hline & Viscous & Park & 0.05 & 12,986 \\
\hline \multirow{4}{*}{$\begin{array}{l}\text { Middle Point } \\
\text { and [20] model }\end{array}$} & Inviscid & Dunn and Kang & 0.05 & 10,560 \\
\hline & Inviscid & Park & 0.05 & 10,642 \\
\hline & Viscous & Dunn and Kang & 0.05 & 17,194 \\
\hline & Viscous & Park & 0.05 & 16,372 \\
\hline \multirow{4}{*}{$\begin{array}{l}\text { Middle Point } \\
\text { and [21] model }\end{array}$} & Inviscid & Dunn and Kang & 0.05 & 18,272 \\
\hline & Inviscid & Park & 0.05 & 17,868 \\
\hline & Viscous & Dunn and Kang & 0.05 & 12,883 \\
\hline & Viscous & Park & 0.05 & 12,967 \\
\hline
\end{tabular}




\section{Conclusions}

In this work, a study involving magnetic field actuation over reentry flows in thermochemical nonequilibrium condition is performed. The Euler and Navier-Stokes equations, on conservative and finite volume contexts, employing structured spatial discretization, are studied. The numerical algorithm of Maciel is used to perform the reentry flow numerical experiments, which give us an original contribution to the CFD community. Two types of numerical dissipation models are applied, namely: [20-21]. The "hot gas" hypersonic flow around a blunt body, in two-dimensions, is simulated. The convergence process is accelerated to steady state condition through a spatially variable time step procedure, which has proved effective gains in terms of computational acceleration ([22-23]). Two time integration methods are tested to march the scheme in time, and it is another original contribution of this work. They are: Euler Backward, and Middle Point. The reactive simulations involve Earth atmosphere chemical model of eleven species. The [24] model with thirty-two reactions and the [25] model with forty-three reactions are taken into account. The work of [26] is the reference one to couple the fluid dynamics and Maxwell equations of electromagnetism based on a conservative and finite volume formalisms. The results have indicated that the Maciel scheme employing the [24] chemical model, using the [20] artificial dissipation operator and the Euler Backward method to march in time, for the inviscid case, yields the best prediction of the stagnation pressure value. Moreover, the shock-standoff distance did not suffer alteration with the increase of the magnetic field intensity, opposed to the perfect gas behavior, the drag coefficient reduces in value with the increase of the magnetic field intensity, corroborating the perfect gas results. Finally, the temperature peak is reduced with the increase of the magnetic field intensity, also corroborating the perfect gas behavior.

This work is the couple of the [27] study, involving perfect gas magnetic actuation, and [28-29] study, involving reactive reentry flows, in two-dimensions.

\section{Acknowledgements}

The author would like to thank the infrastructure of ITA that allowed the realization of this work. He would also like to thank the CAPES by the financial support conceded under the form of a scholarship.

\section{Competing Interests}

Author has declared that no competing interests exist.

\section{References}

[1] Narayan JR, Girimaji SS. Turbulent reacting flow computations including turbulence-chemistry interactions. AIAA Paper 92-0342; 1992.

[2] Gnoffo PA, Gupta RN, Shinn JL. Conservation Equations and physical models for hypersonic flows in thermal and chemical nonequilibrium. NASA TP 2867; 1989.

[3] Liu M, Vinokur M. Upwind algorithms for general thermo-chemical nonequilibrium flows. AIAA Paper 89-0201; 1989.

[4] Park C. Radiation enhancement by nonequilibrium in earth's atmosphere. Journal of Spacecraft and Rockets. 1985;22(1):27-36.

[5] Park C. Problem of rate chemistry in the flight regimes of aeroassissted orbital transfer vehicles", thermal design of aeroassissted orbital transfer vehicles. Progress in Astronautics and Aeronautics. edited by H. F. Nelson. AIAA, NY. 1985;96:511-537. 
[6] Gnoffo PA. Three-dimensional AOTV flowfields in chemical nonequilibrium. AIAA Paper 86-0230; 1986.

[7] Li CP. Implicit methods for computing chemically reacting flow. NASA TM-58274; 1986.

[8] Lee JH. Basic governing equations for the flight regimes of aeroassisted orbital transfer vehicles. Thermal Design of Aeroassisted Transfer Vehicles. Progress in Astronautics and Aeronautics, AIAA. 1985;96:3-53.

[9] Park C. Convergence of computation of chemically reacting flows. Thermophysical Aspects of Reentry Flows. Progress in Astronautics and Aeronautics. Edited by J. N. Moss and C. D. Scott. AIAA, NY. 1986;103:478-513.

[10] Park C. Assessment of two-temperature kinetic model for dissociating and weakly-ionizing nitrogen. AIAA Paper 86-1347; 1986.

[11] Park C. Calculation of nonequilibrium radiation in the flight regimes of aeroassissted orbital transfer vehicles. Thermal Design of Aeroassissted Orbital Transfer Vehicles. Progress in Astronautics and Aeronautics. Edited by H. F. Nelson, AIAA, NY. 1985;96:395-418.

[12] Park C. Nonequilibrium Air Radiation (NEQAIR) program: User's manual. NASA TM-86707; 1985.

[13] Davidson PA. Magnetohydrodynamics in materials processing. Ann. Rev. Fluid Mech. 1999;31:273300 .

[14] Ziemer RW, Bush WB. Magnetic field effects on bow shock stand-off distance. Physical Review Letters. 1958;1(2):58-59.

[15] Meyer RX. Magnetohydrodynamics and aerodynamic heating. ARS Journal. 1959;29(3):187-192.

[16] Gurijanov EP, Harsha PT. AJAX: New directions in hypersonic technology. AIAA Paper 96-4609; 1996.

[17] Brichkin DI, Kuranov AL, Sheikin EG. MHD-technology for scramjet control. AIAA Paper 98-1642; 1998.

[18] Ganiev YC, Gordeev VP, Krasilnikov AV, Lagutin VI, Otmennikov VN, Panasenko AV. Theoretical and experimental study of the possibility of reducing aerodynamic drag by employing plasma injection. AIAA Paper 99-0603; 1999.

[19] Adamovich IV, Subramanian VV, Rich JW, Macheret SO. Phenomenological analysis of shock-wave propagation in weakly ionized plasmas. AIAA Journal. 1998;36(5):816-822.

[20] Mavriplis DJ. Accurate multigrid solution of the Euler equations on unstructured and adaptive meshes. AIAA Journal. 1990;28(2):213-221.

[21] Turkel E, Vatsa VN. Effect of artificial viscosity on three-dimensional flow solutions. AIAA Journal. 1994;32(1):39-45.

[22] Maciel ESG. Simulations in 2D and 3D applying unstructured algorithms, Euler and Navier-Stokes Equations - Perfect gas formulation. Saarbrücken, Deutschland: Lambert Academic Publishing (LAP). 2015;Ch. 1:26-47. 
[23] Maciel, ESG. Simulations in 2D and 3D applying unstructured algorithms, Euler and Navier-Stokes Equations - Perfect gas formulation. Saarbrücken, Deutschland: Lambert Academic Publishing (LAP). 2015;Ch. 6:160-181.

[24] Dunn MG, Kang SW. Theoretical and experimental studies of reentry plasmas. NASA CR-2232; 1973.

[25] Park C. Assessment of two-temperature kinetic model for ionizing air. Journal of Thermophysics and Heat Transfer. 1989;3(13):233-244.

[26] Gaitonde DV. Development of a Solver for 3-D Non-Ideal Magnetogasdynamics. AIAA Paper 99$3610 ; 1999$.

[27] Maciel ESG. Magnetic formulation and first-order schemes in 2D and 3D, Euler, Navier-Stokes and Maxwell Equations in 2D and 3D - Perfect gas formulation. Saarbrücken, Deutschland: Lambert Academic Publishing (LAP). 2015;Ch. 7:225-290.

[28] Maciel ESG. Hypersonic reactive flow simulations in two-dimensions, chemical and Thermochemical non-equilibrium conditions. Saarbrücken, Deutschland: Lambert Academic Publishing (LAP). 2015; Ch. 7:491-589.

[29] Maciel ESG. Hypersonic reactive flow simulations in two-dimensions, chemical and Thermochemical non-equilibrium conditions. Saarbrücken, Deutschland: Lambert Academic Publishing (LAP). 2015; Ch. 8:590-687.

[30] Prabhu RK. An implementation of a chemical and thermal nonequilibrium flow solver on unstructured meshes and application to blunt bodies. NASA CR-194967; 1994.

[31] Saxena SK, Nair MT. An improved roe scheme for real gas flow. AIAA Paper 2005-587; 2005.

[32] Ait-Ali-Yahia D, Habashi WG. Finite Element adaptive method for hypersonic thermochemical nonequilibrium flows. AIAA Journal. 1997;35(8):1294-1302.

[33] Long LN, Khan MMS, Sharp HT. Massively parallel three-dimensional Euler/Navier-Stokes method. AIAA Journal. 1991;29(5):657-666.

[34] Vincent WG,. Kruger Jr. CH. Introduction to physical gas dynamics. Malabar, Florida, EUA: Krieger Publishing Company. 2002;Ch. 1:1-26.

[35] Fox RW, McDonald AT. Introdução à Mecânica dos Fluidos. Guanabara Editor; 1988.

[36] Maciel ESG. Simulação Numérica de Escoamentos Supersônicos e Hipersônicos Utilizando Técnicas de Dinâmica dos Fluidos Computacional. PhD Thesis, ITA, CTA, São José dos Campos, SP, Brazil; 2002.

[37] Anderson Jr. JD. Fundamentals of aerodynamics. McGraw-Hill, Inc., $5^{\text {th }}$ Edition. 2010;1008.

(C) 2017 Maciel; This is an Open Access article distributed under the terms of the Creative Commons Attribution License (http://creativecommons.org/licenses/by/4.0), which permits unrestricted use, distribution, and reproduction in any medium, provided the original work is properly cited.

Peer-review history:

The peer review history for this paper can be accessed here (Please copy paste the total link in your

browser address bar)

http://sciencedomain.org/review-history/21384 